Article

\title{
Synthesis and in Silico Evaluation of Novel Compounds for PET-Based Investigations of the Norepinephrine Transporter
}

\author{
Catharina Neudorfer ${ }^{1,2, *}$, Amir Seddik ${ }^{3}$, Karem Shanab ${ }^{1,2}$, Andreas Jurik ${ }^{3}$, \\ Christina Rami-Mark ${ }^{1}$, Wolfgang Holzer ${ }^{2}$, Gerhard Ecker ${ }^{3}$, Markus Mitterhauser ${ }^{1}$, \\ Wolfgang Wadsak ${ }^{1}$ and Helmut Spreitzer ${ }^{2, *}$
}

1 Department of Biomedical Imaging and Image-guided Therapy, Division of Nuclear Medicine, Medical University of Vienna, Waehringer Guertel 18-20, 1090 Vienna, Austria;

E-Mails: karem.shanab@gmail.com (K.S.); christina.rami-mark@meduniwien.ac.at (C.R.-M.); markus.mitterhauser@meduniwien.ac.at (M.M.); wolfgang.wadsak@meduniwien.ac.at (W.W.)

2 Division of Drug Synthesis, Department of Pharmaceutical Chemistry, Faculty of Life Sciences, University of Vienna, Althanstraße 14, 1090 Vienna, Austria;

E-Mail: wolfgang.holzer@univie.ac.at

3 Division of Drug Design and Medicinal Chemistry, Department of Pharmaceutical Chemistry, Faculty of Life Sciences, University of Vienna, Althanstraße 14, 1090 Vienna, Austria;

E-Mails: amir.seddik@univie.ac.at (A.S.); andreas.jurik@univie.ac.at (A.J.); gerhard.f.ecker@univie.ac.at (G.E.)

* Authors to whom correspondence should be addressed;

E-Mails: catharina.neudorfer@gmail.com (C.N.); helmut.spreitzer@univie.ac.at (H.S.);

Tel.: +43-4277-55629 (C.N.); +43-4277-55621 (H.S.);

Fax: +43-4277-855629 (C.N.); +43-4277-855621 (H.S.).

Academic Editor: Svend Borup Jensen

Received: 20 November 2014 / Accepted: 14 January 2015 / Published: 20 January 2015

\begin{abstract}
Since the norepinephrine transporter (NET) is involved in a variety of diseases, the investigation of underlying dysregulation-mechanisms of the norepinephrine (NE) system is of major interest. Based on the previously described highly potent and selective NET ligand 1-(3-(methylamino)-1-phenylpropyl)-3-phenyl-1,3-dihydro-2H-benzimidaz- ol2-one (Me@APPI), this paper aims at the development of several fluorinated methylaminebased analogs of this compound. The newly synthesized compounds were computationally
\end{abstract}


evaluated for their interactions with the monoamine transporters and represent reference compounds for PET-based investigation of the NET.

Keywords: NET; ADHD; cocaine dependence; BAT; PET; FAPPI

\section{Introduction}

Abnormal regulation of the norepinephrine transporter (NET) or NET dysfunction, respectively, cause either increased or decreased levels of norepinephrine (NE) in the synaptic cleft. Since NE is a fundamental neurochemical messenger, its accurate regulation is of major importance. Thus, the NET, responsible for NE equilibrium in the synaptic cleft, is representing the reuptake site and considered to be involved in a variety of neurological/psychiatric disorders [1,2], but also plays a pivotal role in cardiovascular [1-3] and metabolic diseases [3-5]. Reduced NET levels go along with neurological disorders like major depression [6,7], Parkinson's disease (PD), Alzheimer's disease (AD) [8-18], and cardiovascular diseases such as hypertension, cardiomyopathy, and heart failure $[5,13]$. Furthermore, a dysfunction of the NE system was reported in Attention Deficit Hyperactivity Disorder (ADHD) [9, 17,19], suicide $[1,12,20]$, substance abuse (cocaine dependence) [16], and schizophrenia [10]. A more recent discovery is the involvement of the NET in diseases like diabetes and obesity, due to its presence in brown adipose tissue (BAT) and the proposed activation thereof via NE [4,5,21].

Based on the fact that the NET is involved in such a variety of diseases, the investigation of the underlying dysregulation-mechanism of the NE system is of major interest. For this purpose, information about the transporter abundance and density in healthy and pathological living human brains is required. The most suitable and accurate technique to gain this information is positron emission tomography (PET). As a non-invasive molecular imaging technique, it represents a suitable approach towards the collection of missing data in the living organism and direct quantification of receptor/transporter densities in vivo. To fully gain insight in the molecular changes of the noradrenergic system via PET, however, prior development of suitable NET PET radioligands is required.

So far, radiolabeled NET binding reboxetine analogs $\left[{ }^{11} \mathrm{C}\right] \mathrm{MeNER},\left[{ }^{11} \mathrm{C}\right] \mathrm{MRB},\left((S, S)-2-\left(\alpha-\left(2-\left[{ }^{11} \mathrm{C}\right]-\right.\right.\right.$ methoxyphenoxy)benzyl)morpholine) and $\left[{ }^{18} \mathrm{~F}\right] \mathrm{FMeNER}-\mathrm{D}_{2}\left((S, S)-2-\left(\alpha-\left(2-\left[{ }^{18} \mathrm{~F}\right]\right.\right.\right.$ fluoro $\left[{ }^{2} \mathrm{H}_{2}\right]$ methoxyphenoxy)benzyl)morpholine) have been described, which however display certain limitations such as metabolic instability, complex radiosyntheses, or late equilibria [22-26].

Recently, Zhang et al. [26] evaluated a series of benzimidazolone-based propanamines with in vitro inhibitory activity on the human norepinephrine transporter (hNET). The results of these investigations suggested that compounds containing a phenyl moiety directly attached at the benzimidazolone ring (e.g., 1, Figure 1) were the most potent, representing a half maximal inhibitory concentration (IC50) below $10 \mathrm{nM}\left(\mathrm{IC}_{50}<10 \mathrm{nM}\right)$. Furthermore, hNET selectivity over human serotonin transporter (hSERT) turned out $>300$-fold superior to those of reboxetine and atomoxetine (16- and 81-fold) [26]. Fluorination at position 2 of the phenyl moiety attached to the benzimidazolone ring (e.g., 2, Figure 1), indicated similar hNET potency, comparable to its non-fluorinated analogs (e.g., 1) and additionally exhibited hNET selectivity over hSERT (80-fold) similar to atomoxetine [26]. 

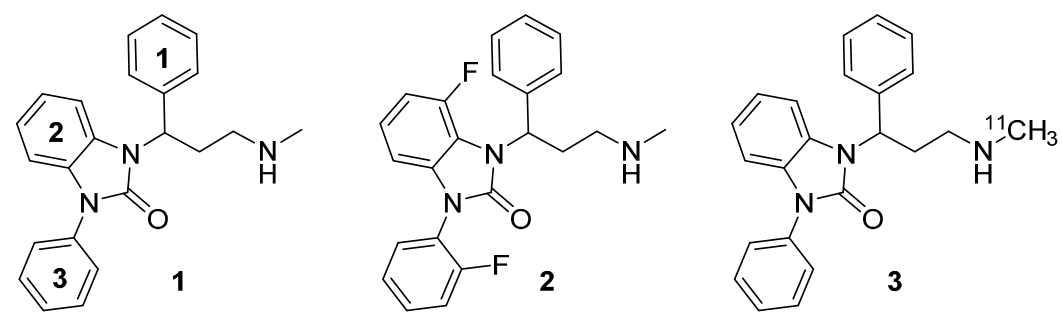

Figure 1. Structures of the highly potent and selective NET ligands 1-(3-(methylamino)- 1phenylpropyl)-3-phenyl-1,3-dihydro-2H-benzimidazol-2-one (Me@APPI, 1) and 4-fluoro- 1(2-fluorophenyl)-3-(3-(methylamino)-1-phenylpropyl)-1,3-dihydro-2H-benzimidazol-2one (2) as well as radiolabeled analog $\left[{ }^{11} \mathrm{C}\right] \mathrm{Me} @ \mathrm{APPI}(\mathbf{3})$.

Both benzimidazolone derived propanamines with a phenyl moiety (e.g., 1), as well as a fluorinated phenyl moiety (as in 2) indicated excellent hNET selectivity over human dopamine transporter (hDAT) with $<50 \%$ inhibition of the cocaine analog $\left[{ }^{3} \mathrm{H}\right] \mathrm{WIN}-35,428$, binding to hDAT at a concentration of $10 \mu \mathrm{M}$ [26]. Given those findings, both described benzimidazolone-based propanamines 1 and 2 represent excellent candidates for selective and potent NET inhibition with high affinity and low unspecific binding. Thus, on the basis of the results of Zhang et al. [26] the methylamino moiety of the core compound 1 has been radiolabeled with ${ }^{11} \mathrm{C}$ and tested by our research group [27]. All investigated preclinical parameters, such as affinity, blood brain barrier penetration, lipophilicity, metabolic degradation, and selectivity showed excellent results, thus suggesting suitability of ${ }^{11} \mathrm{C}$-radiolabeled 1-(3-(methylamino)-1-phenylpropyl)-3-phenyl-1,3-dihydro-2H-benzimidazole-2-one ([ $\left.\left.{ }^{11} \mathrm{C}\right] \mathrm{Me} @ \mathrm{APPI}\right)$ $(3$, Figure 1$)$ as a NET radioligand for use in PET.

Due to successful preclinical testing of $\left[{ }^{11} \mathrm{C}\right] \mathrm{Me} @ \mathrm{APPI}(3)$ and given the excellent in vitro results of compound 2, shown by Zhang et al. [26] the aim of this paper is the synthesis and docking studies of several fluorinated analogs 4-6 of compound 1 (Figure 2) as reference compounds for their later prepared radioactive analogs. All methylamine-derived benzimidazolone derivatives $\mathbf{4}-\mathbf{6}$ will be subjected to affinity, selectivity, and lipophilicity studies towards the NET as well as blood brain barrier penetration experiments at the Medical University of Vienna. The most promising NET ligands will then be selected for the development of new, selective PET tracers for the NET and after radiolabeling with both ${ }^{11} \mathrm{C}$ and ${ }^{18} \mathrm{~F}$, they will be the subject of further experiments.
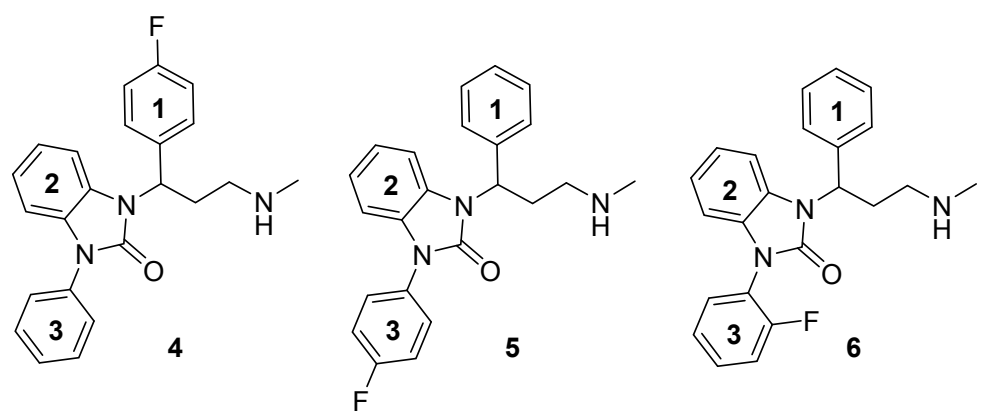

Figure 2. Chemical structure of envisaged reference compounds 4-6 (FAPPI:1-3). 


\section{Results and Discussion}

The synthesis of reference compounds 4-6 first required the preparation of side chains $\mathbf{1 1}$ and 12, as well as core compounds 16-18. After successful preparation, side chain 11 was merged in a condensation reaction with core compound 16, whereas side chain 12 was reacted with core compounds 17 and 18, prior to halogen exchange and substitution with methylamine (Scheme 1).

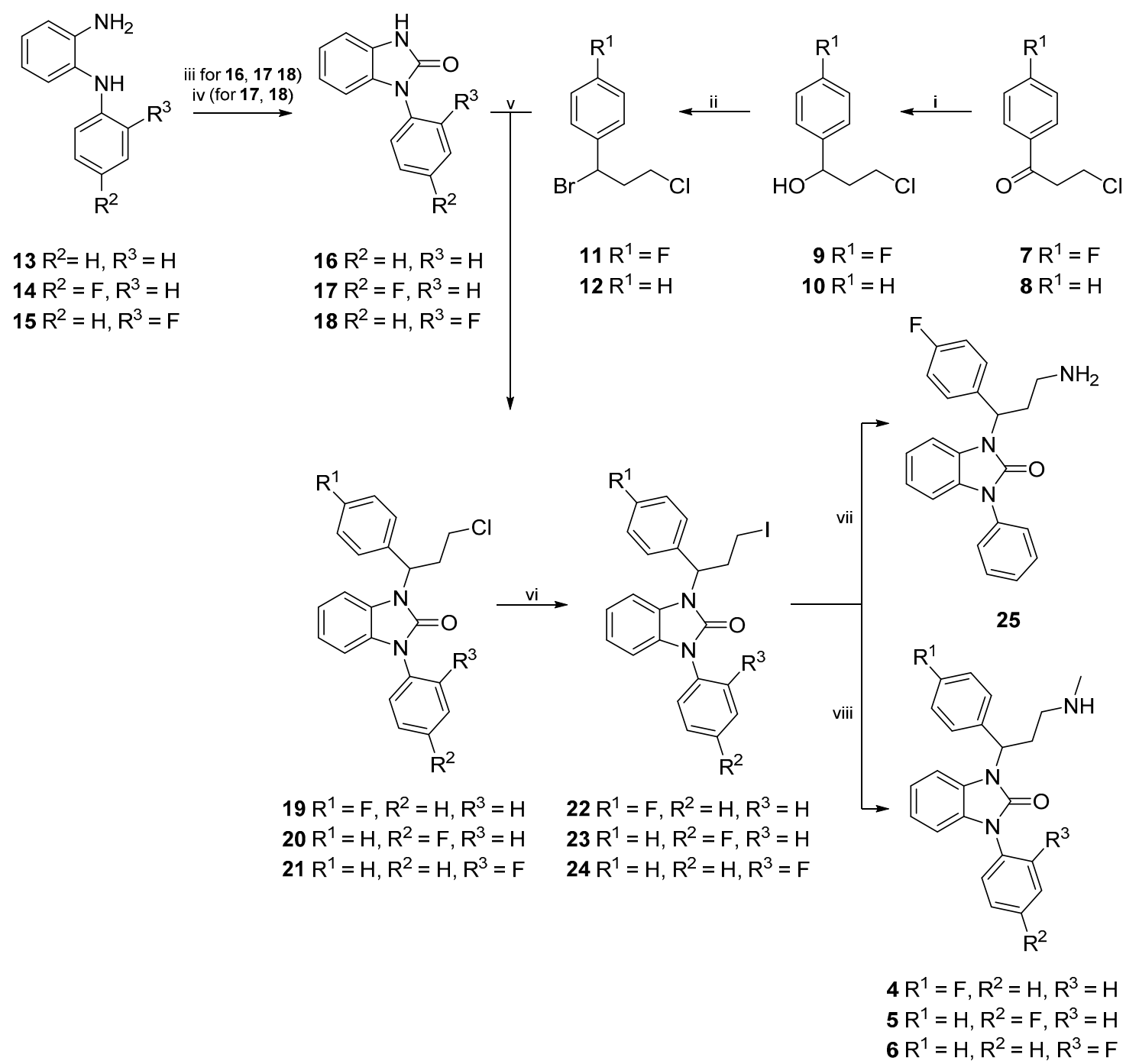

Reagents and conditions: (i) THF, EtOH, $\mathrm{NaBH}_{4},-10{ }^{\circ} \mathrm{C} \rightarrow-5{ }^{\circ} \mathrm{C}, 10$ min, yields for 9: $95 \%$, 10: 100\%; (ii) aq. HBr, rt, 3 h, yields for 11: $64 \%, 12: 86 \%$; (iii) 1,1'-carbonyldiimidazole, anhyd. THF, rt, overnight, yields for 16: 74\%, 17: 61\%, 18: 69\%; (iv) 1,1'-carbonyldiimidazole, anhyd. DMF, $90{ }^{\circ} \mathrm{C}, 2 \mathrm{~h}$, yields for 17: 80\%, 18: 80\%; (v) $\mathrm{K}_{2} \mathrm{CO}_{3}$, DMF, rt, $30 \mathrm{~min} \rightarrow$ addition of $\mathbf{1 1}$ and $\mathbf{1 2} \rightarrow \mathrm{rt}$, $30 \mathrm{~min}$, yields for 19: 32\%, 20: 63\%, 21: 55\%; (vi) NaI, acetone, reflux, $24 \mathrm{~h}$, yields for $22: 82 \%, \mathbf{2 3}$ : 76\%, 24: 53\%; (vii) $\mathrm{NH}_{3}$ in isopropanol, $80{ }^{\circ} \mathrm{C}, 3 \mathrm{~h}$, yield for 25: 50\%; (viii) methylamine in $\mathrm{EtOH}$, $80{ }^{\circ} \mathrm{C}, 3 \mathrm{~h}$, yields for $4: 48 \%, 5: 29 \%, 6: 30 \%$.

Scheme 1. Synthesis of compounds 4-6.

For the synthesis of side chains $\mathbf{1 1}$ and 12, a protocol of Varney et al. [28] was adopted and the keto group of commercially available compounds $\mathbf{7}$ and $\mathbf{8}$ was reduced with sodium borohydride in order to 
obtain intermediate alcohols 9 and 10. Subsequent bromination of 9 and $\mathbf{1 0}$ with aqueous hydrogen bromide led to the formation of products 11 and 12, respectively.

Core compound 16 was prepared by the reaction of commercially available $N$-phenylbenzene-1,2diamine (13) with 1,1'-carbonyldiimidazole. For the preparation of 17 and 18 however, 14 and 15 first had to be made accessible (Scheme 2). Thus, 1-fluoro-2-nitrobenzene (26) reacted with commercially available fluoroanilines $\mathbf{2 7}$ and 28, respectively, to obtain disubstituted amines $\mathbf{2 9}$ and $\mathbf{3 0}$. Therefore, two different methods were applied (Scheme 2): The first method (i) was conducted by heating 26 and 27 with anhydrous potassium fluoride and potassium carbonate in a microwave oven [29]. Since the adoption of an alternative method [30] — conventional heating at $180{ }^{\circ} \mathrm{C}$-gave compound 29 in higher yields, this approach (ii) was chosen for the large scale synthesis of $\mathbf{2 9}$ as well as for the preparation of $\mathbf{3 0 .}$

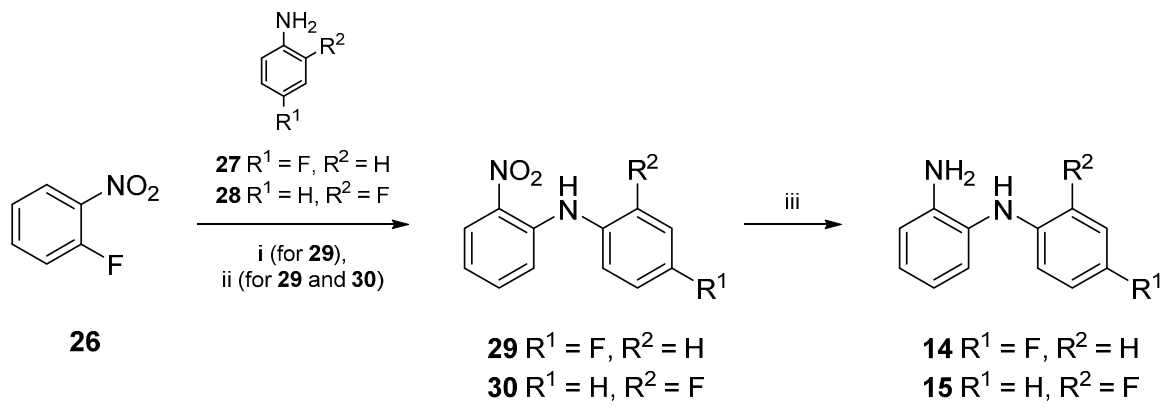

Reagents and conditions: (i) anhyd. $\mathrm{KF}, \mathrm{K}_{2} \mathrm{CO}_{3}$, microwave oven, $900 \mathrm{~W}, 10 \mathrm{~min}$, yields for 29: $58 \%$; (ii) anhyd. $\mathrm{KF}, \mathrm{K}_{2} \mathrm{CO}_{3}, 180{ }^{\circ} \mathrm{C}, 2 \mathrm{~d}$, yields for 29: 68\%, 30: 52\%; (iii) $\mathrm{Zn}, \mathrm{AcOH}, 0{ }^{\circ} \mathrm{C} \rightarrow \mathrm{rt}, 2 \mathrm{~h}$, yields for 14 : $93 \%, 15$ : n.d.

Scheme 2. Synthesis of compounds 14-15.

In the next reaction step, the nitro groups of both disubstituted amines $\mathbf{2 9}$ and $\mathbf{3 0}$ were reduced. For this purpose $\mathbf{2 9}$ or $\mathbf{3 0}$ were added to a mixture of zinc/acetic acid. The resulting amines $\mathbf{1 4}$ or $\mathbf{1 5}$ were obtained in excellent yields (Scheme 2) [30].

Freshly prepared intermediates $\mathbf{1 4}$ and $\mathbf{1 5}$ were then subjected to a cyclization reaction with 1,1'-carbonyldiimidazole in DMF under anhydrous conditions (Scheme 1) by modifying a synthesis protocol according to Zhang et al. [26]. DMF was preferred over THF to ensure higher yields and shorter reaction times.

Condensation reactions of benzimidazolones 16, 17, and 18 with side chains 11 and 12, respectively were performed under basic conditions (Scheme 1) by adapting a procedure of Jona et al. [31]. After purification, the chloro-substituted derivatives 19-21 were converted into the iodo compounds 22-24 in a Finkelstein reaction. Target compounds 4-6 (FAPPI:1-3) were then obtained by heating derivatives 22-24 in a solution of methylamine in ethanol in a sealed tube for $3 \mathrm{~h}$. In addition to reference compounds 4-6, free amine 25 was synthesized by dissolving 22 in a solution of ammonia in isopropanol and heating the resulting mixture in a sealed tube for $3 \mathrm{~h}$. As compound 25 features a free amine moiety, it can be considered a precursor for radiosynthesis.

Since compounds $\mathbf{4}$ and $\mathbf{5}$ comprise a novel fluoro substitution, a computational docking study was performed to assess if these compounds still would fit in the binding site of the NET. Furthermore, we aimed at creating a binding mode hypothesis which allows gaining insights into the molecular basis of binding and selectivity towards the monoamine transporters. As the basic scaffold has been shown to act in 
an enantioselective manner, the respective $(R)$ enantiomers were used throughout the docking studies [26]. The ligands were docked in the substrate binding site (S1) of the outward-open conformation of the transporter models (see Experimental Section for details), since related inhibitors, such as nortriptyline, sertraline, mazindol, etc. were also shown to fit in the S1 of the Drosophila DAT (dDAT) and the "SERT"-ized leucine transporter ("LeuBAT") in the same protein conformation [32,33]. Interestingly, the co-crystallized ligand in dDAT, nortriptyline (31), has the same ranking of human NET, SERT and DAT activity as reference compound 1, i.e., 4.4, 18 and $1149 \mathrm{nM} \mathrm{K} \mathrm{K}_{\mathrm{D}} v$ s. 9, 2995 and >10,000 $\mathrm{nM} \mathrm{IC}_{50}$, respectively [26,34]. Additionally, nortriptyline shares important structural features with the benzimidazolones, i.e., two aromatic moieties and an $\mathrm{N}$-methyl-ethylenamine side chain. Therefore their binding mode can be expected to be similar.

Common scaffold clustering [35] revealed two binding hypotheses (see Experimental Section) which indicated that compounds 4-6 fit in the S1 of all three transporters. Hence, additional fluorination does not seem to cause steric clashes. In both hypotheses, the most prominent protein-ligand interaction was the cationic nitrogen atom placed in the A sub pocket [36], located between the central Asp75/98/79 side chain as a salt-bridge and the Phe72/95/76 side chain as a cation-pi interaction in NET/SERT/DAT, respectively. This is well in accordance with the X-ray structures of the templates. Additional pi-pi stacking interactions with Phe152/176/156 and Phe323/355/341 further promote the binding in both hypotheses obtained:

Hypothesis 1: the benzimidazolone heterocycle (ring 2) is placed in the B sub pocket and ring 3 in the $\mathrm{C}$ pocket, whereas ring 1 is solvent exposed (see figure in Experimental Section).

Hypothesis 2: Ligand ring 1 is placed in the B pocket whereas ring 2 is placed at the same height (measured from the membrane-water interface) and overlap with the rings of nortriptyline (31, Figure 3). The solvent exposed Tyr151/Tyr175/Phe155 in NET/SERT/DAT, resp. T-stacks with ring 2 whereas ring 3 points extracellularly (Table 1, Figure 4).

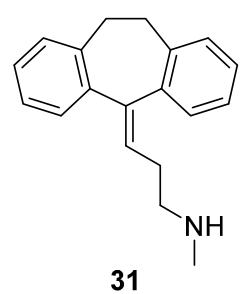

Figure 3. Chemical structure of nortriptyline (co-crystallized ligand from the template, PDB code 4M48) [28].

Table 1. Sequence alignment of all distinct monoamine transporter residues located in sub sites (reference [32]) in the vicinity of the docked compounds. Red: hydrophilic side chain, green: lipophilic side chain, bold: bulkier side chain.

\begin{tabular}{cccccccccc}
\hline & B Site & & \multicolumn{3}{c}{ C Site } & \multicolumn{3}{c}{ Outer Site } \\
\hline hNET & S420 & M424 & G149 & V148 & A145 & F72 & D473 & Y151 & A477 \\
hSERT & T439 & L443 & A173 & I172 & A177 & Y95 & E493 & Y175 & T497 \\
hDAT & A423 & M427 & G153 & V152 & S149 & F76 & D476 & F155 & A480 \\
\hline
\end{tabular}




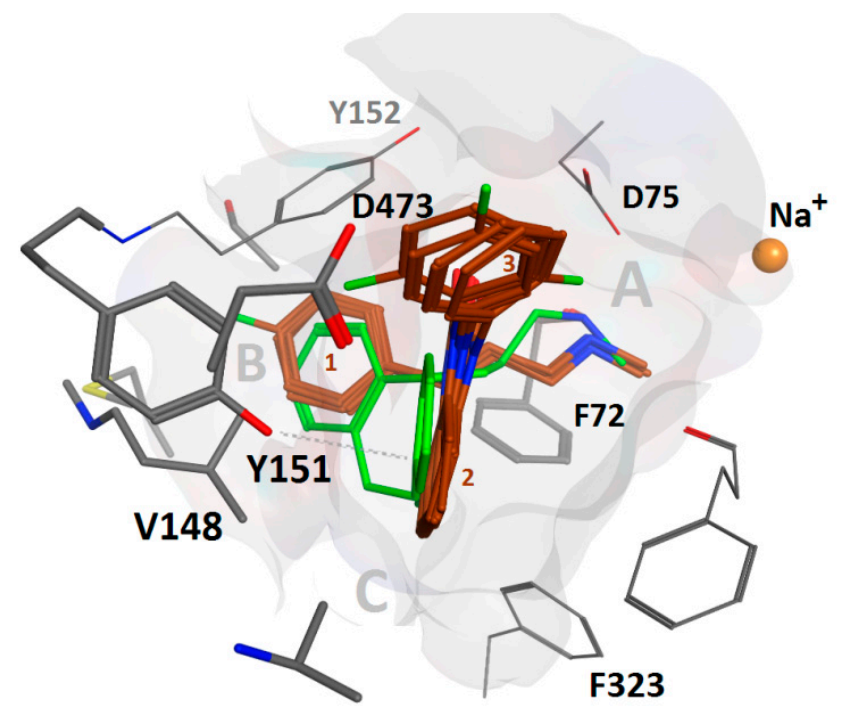

Figure 4. Overlay of compounds 1, 2, and 4-6 (maroon) in binding hypothesis 2 in hNET showing agreement with the co-crystal pose of nortriptyline (31) (green). Val148 and Asp473 allow more space than Ile172 and Glu439 in hSERT, resp., whereas Tyr151 might induce a more potent stacking interaction as compared to Phe155 in hDAT. The angle between ligand ring 2 and 3 is almost $90^{\circ}$ in all poses. The extracellular space is located above.

As binding hypothesis 2 is in close agreement with the co-crystallized ligands in dDAT and LeuBAT, we focus further analysis on this proposed binding mode. Binding hypothesis 2 indicates why the investigated compounds (4-6) show weaker affinity to SERT and DAT than to NET: lower SERT affinity may be due to Ile172 and Glu439, allowing less space for the ligand to be accommodated as compared to in NET, that comprises a valine and an aspartate at the homologous positions, respectively.

Lower DAT affinity could be ascribed to weaker T stacking interactions of Phe155 as compared to Tyr151 in NET, based on previous findings that a Tyr-Phe pair has a stronger binding energy than a Phe-Phe pair [37].

Since the docking studies indicate that fluorinated methyl amines 4-6 (FAPPI:1-3) bind in an analogous way to the NET as reference compound $\mathbf{1}$ [26], compounds 4-6 will be employed in future studies and evaluated for affinity and selectivity towards the NET. Additionally, lipophilicity studies and blood brain barrier penetration experiments are planned for compounds 4-6 at the Medical University of Vienna. The most promising derivatives regarding their suitability as NET ligands will then be selected for the further development of new and selective PET tracers for the NET, which will comprise either a $\left[{ }^{11} \mathrm{C}\right]$ methylamine, $\left[{ }^{18} \mathrm{~F}\right]$ fluoroalkyl amine or $\left[{ }^{18} \mathrm{~F}\right]$ fluorobenzene radiolabel, respectively. The results of ongoing studies on affinity, selectivity and lipophilicity of the discussed compounds, will be published in a subsequent paper.

\section{Experimental Section}

\subsection{General}

The NMR spectra were recorded from $\mathrm{CDCl}_{3}$ or DMSO- $d_{6}$ solutions on a Bruker DPX200 spectrometer $\left(200 \mathrm{MHz}\right.$ for ${ }^{1} \mathrm{H}, 50 \mathrm{MHz}$ for ${ }^{13} \mathrm{C}$ ) or on a Bruker Avance III 400 spectrometer $(400 \mathrm{MHz}$ 
for ${ }^{1} \mathrm{H}, 100 \mathrm{MHz}$ for ${ }^{13} \mathrm{C}, 40 \mathrm{MHz}$ for ${ }^{15} \mathrm{~N}, 376 \mathrm{MHz}$ for ${ }^{19} \mathrm{~F}$ ) at $25^{\circ} \mathrm{C}$. The center of the solvent (residual) signal was used as an internal standard which was related to TMS with $\delta 7.26 \mathrm{ppm}\left({ }^{1} \mathrm{H}\right.$ in $\left.\mathrm{CDCl}_{3}\right)$, $\delta 2.49 \mathrm{ppm}\left({ }^{1} \mathrm{H}\right.$ in DMSO-d6), $\delta 77.0 \mathrm{ppm}\left({ }^{13} \mathrm{C}\right.$ in $\left.\mathrm{CDCl}_{3}\right)$ and $\delta 39.5 \mathrm{ppm}\left({ }^{13} \mathrm{C}\right.$ in DMSO- $\left.d_{6}\right) .{ }^{15} \mathrm{~N}$ NMR spectra (gs-HMBC, gs-HSQC) were referenced against neat, external nitromethane, ${ }^{19} \mathrm{~F}$ NMR spectra by absolute referencing via $\Xi$ ratio. Digital resolutions were $0.25 \mathrm{~Hz} /$ data point in the ${ }^{1} \mathrm{H}$ and $0.3 \mathrm{~Hz} /$ data point in the ${ }^{13} \mathrm{C}$-NMR spectra. Coupling constants $(J)$ are quoted in Hz. The following abbreviations were used to show the multiplicities: s: singlet, d: doublet, t: triplet, q: quadruplet, dd: doublet of doublet, m: multiplet. Mass spectra were obtained on a Shimadzu QP 1000 instrument (EI, 70 eV), high-resolution mass spectrometry (HRMS) was carried out on a Finnigan MAT 8230 (EI, $10 \mathrm{eV}$ ) or Finnigan MAT $900 \mathrm{~S}$ (ESI, $4 \mathrm{kV}, 3 \mu \mathrm{A}, \mathrm{CH}_{3} \mathrm{CN} / \mathrm{MeOH}$ ) electrospray ionization mass spectrometer with a micro-TOF analyzer. Microwave experiments were carried out in a Synthos 3000 microwave oven (SXQ80 rotor, Anton Paar, Graz, Austria) with an internal temperature probe. Compound purity: all compounds synthesized featured a purity of at least $95 \%$.

\subsection{Syntheses}

\subsubsection{General Procedure for the Synthesis of 9 and $\mathbf{1 0}$}

Starting materials 7 or $\mathbf{8}$, respectively $(1 \mathrm{mmol})$ was dissolved in THF $(1 \mathrm{~mL})$ and EtOH $(1 \mathrm{~mL})$ was added. The mixture was cooled to $-10{ }^{\circ} \mathrm{C}$ and $\mathrm{NaBH}_{4}(1.05 \mathrm{mmol})$ was slowly added at this temperature. The solution was stirred at $-5{ }^{\circ} \mathrm{C}$ for $10 \mathrm{~min}$ and thereafter, poured into a mixture of saturated aqueous ammonium chloride $(3 \mathrm{~mL})$ in ice $(1.5 \mathrm{~g})$. The product was extracted with diethyl ether, dried over $\mathrm{Na}_{2} \mathrm{SO}_{4}$ and evaporated to dryness. The crude product was employed directly in the subsequent reaction step without further purification.

3-Chloro-1-(4-fluorophenyl)propan-1-ol (9). Yield: $4.78 \mathrm{~g}(95 \%)$, pale yellow oil, analytical data are in complete accordance with literature values [38].

3-Chloro-1-phenylpropan-1-ol (10). Yield: $4.61 \mathrm{~g}(99 \%)$, light yellow oil, analytical data are in complete accordance with literature values [28].

\subsubsection{General Procedure for the Synthesis of $\mathbf{1 1}$ and $\mathbf{1 2}$}

To starting material 9 or 10, respectively $(1 \mathrm{mmol})$ was added $48 \%$ aqueous $\mathrm{HBr}(3 \mathrm{~mL})$ and the mixture was stirred for $3 \mathrm{~h}$ at room temperature. Thereafter, the solution was poured into a mixture of $\mathrm{K}_{2} \mathrm{CO}_{3}(1 \mathrm{~g})$ in ice $(5.5 \mathrm{~g})$ and additional solid $\mathrm{K}_{2} \mathrm{CO}_{3}$ was added for neutralization $(\mathrm{pH} 7)$. The crude reaction product was extracted with diethyl ether, the combined organic layers were dried with $\mathrm{MgSO}_{4}$ and evaporated to dryness. The crude product was employed directly in the subsequent reaction step without further purification.

1-(1-Bromo-3-chloropropyl)-4-fluorobenzene (11). Yield: 64\%, pale yellow oil, analytical data are in complete accordance with literature values [39]. 
(1-Bromo-3-chloropropyl)benzene (12). Yield: $5.64 \mathrm{~g}(86 \%)$, yellow oil, analytical data are in complete accordance with literature values [28].

\subsubsection{General Procedure for the Synthesis of $\mathbf{2 9}$ and $\mathbf{3 0}$}

4-Fluoroaniline or 2-fluoroaniline, respectively ( $1 \mathrm{mmol})$, anhydrous $\mathrm{KF}$ (1 mmol), and $\mathrm{K}_{2} \mathrm{CO}_{3}$ $(1 \mathrm{mmol})$ were well powdered with a mortar and a pestle, then 1-fluoro-2-nitrobenzene (1 mmol) was added and the mixture was stirred for 2 days at $180{ }^{\circ} \mathrm{C}$. Thereafter, water $(5 \mathrm{~mL})$ and $\mathrm{CH}_{2} \mathrm{Cl}_{2}(5 \mathrm{~mL})$ were added and the organic layer was washed with $10 \% \mathrm{HCl}(5 \mathrm{~mL})$ and brine $(5 \mathrm{~mL})$. The combined organic layers were dried over $\mathrm{Na}_{2} \mathrm{SO}_{4}$ and evaporated to dryness prior to purification by column chromatography.

N-(4-Fluorophenyl)-2-nitroaniline (29). Yield: $68 \%$, dark orange crystals, mp. $82-83{ }^{\circ} \mathrm{C}$, purification: silica gel 60, petroleum ether/ethyl acetate 9:1 and RP-18 silica gel, methanol/water 7:3, analytical data are in complete accordance with literature values [29].

2-Fluoro- $N$-(2-nitrophenyl)aniline (30). Yield: $52 \%$, orange crystals, $\mathrm{mp} .79-80{ }^{\circ} \mathrm{C}$, purification: silica gel 60, petroleum ether/ethyl acetate 9:1, analytical data are in complete accordance with literature values [40].

\subsubsection{Alternative Procedure for the Synthesis of 29}

4-Fluoroaniline (7.89 g, $6.73 \mathrm{~mL}, 70.87 \mathrm{mmol}$ ), anhydrous $\mathrm{KF}$ (4.13 g, $70.87 \mathrm{mmol})$, and $\mathrm{K}_{2} \mathrm{CO}_{3}$ (9.81 g, $70.87 \mathrm{mmol})$ were well powdered with a mortar and a pestle, then 1-fluoro-2-nitrobenzene $(10.00 \mathrm{~g}, 7.47 \mathrm{~mL}, 70.87 \mathrm{mmol})$ was added and the mixture was irradiated in the microwave (900 W, $10 \mathrm{~min})$. Thereafter, water $(8 \mathrm{~mL})$ and $\mathrm{CH}_{2} \mathrm{Cl}_{2}(10 \mathrm{~mL})$ were added and the organic layer was washed with $10 \% \mathrm{HCl}(5 \mathrm{~mL})$ and brine $(5 \mathrm{~mL})$. The combined organic layers were dried over $\mathrm{Na}_{2} \mathrm{SO}_{4}$ and evaporated to dryness prior to purification by column chromatography (silica gel 60, petroleum ether/ethyl acetate $9.5: 0.5)$. Yield: $9.51 \mathrm{~g}(58 \%)$, dark orange crystals, $\mathrm{mp} .82{ }^{\circ} \mathrm{C}-83^{\circ} \mathrm{C}$.

\subsubsection{General Procedure for the Synthesis of $\mathbf{1 4}$ and $\mathbf{1 5}$}

To a solution of $\mathrm{Zn}^{0}(13.8 \mathrm{mmol})$ in glacial acetic acid $(1 \mathrm{~mL})$ was added starting material 28 or 29 $(1 \mathrm{mmol})$ at $0{ }^{\circ} \mathrm{C}$ under argon atmosphere. After the addition, the mixture was allowed to warm to room temperature and was stirred for $2 \mathrm{~h} . \mathrm{Zn}^{0}$ was filtered off and the $\mathrm{pH}$ of the solution was adjusted to $\mathrm{pH} 9$ with $2 \mathrm{~N} \mathrm{NaOH}$. Thereafter, the aqueous layer was extracted three times with $\mathrm{CH}_{2} \mathrm{Cl}_{2}$, the combined organic layers were dried over $\mathrm{MgSO}_{4}$ and evaporated to dryness.

N-(4-Fluorophenyl)benzene-1,2-diamine (14). Yield: 93\%, dark orange-reddish oil, purification: silica gel 60, petrol ether/ethyl acetate 9:1, analytical data are in complete accordance with literature values [30].

$N$-(2-Fluorophenyl)benzene-1,2-diamine (15). The crude reaction product was subjected to the next reaction step without further purification. 


\subsubsection{General Procedure for the Synthesis of 16-18}

To a solution of starting materials $\mathbf{1 3}, \mathbf{1 4}$, or $\mathbf{1 5}$ (1 mmol) in THF was added 1,1'-carbonyldiimidazole $(1.4 \mathrm{mmol})$ under argon atmosphere and the mixture was stirred at room temperature overnight. Thereafter, the crude reaction product was purified by column chromatography.

1-Phenyl-1,3-dihydro-2H-benzimidazol-2-one (16). Yield: $0.85 \mathrm{~g}$ (74\%), pink crystals, mp. $201{ }^{\circ} \mathrm{C}-202{ }^{\circ} \mathrm{C}$, THF: $10 \mathrm{~mL}$, purification: silica gel 60, petroleum ether/ethyl acetate 1:1, analytical data are in complete accordance with literature values [41].

1-(4-Fluorophenyl)-1,3-dihydro-2H-benzimidazol-2-one (17). Yield: 61\%, brown resin, THF: $25 \mathrm{~mL}$, purification: silica gel 60, petroleum ether/ethyl acetate 9:1, ${ }^{1} \mathrm{H}-\mathrm{NMR}\left(200 \mathrm{MHz}, \mathrm{CDCl}_{3}\right): \delta(\mathrm{ppm})$ 6.74-6.81 (m, 2H), 6.89-7.11 (m, 2H), 7.14-7.23 (m, 2H), 7.48-7.59 (m, 1H), 7.73-7.78 (m, 1H), 9.03 (br s, $1 \mathrm{H}),{ }^{13} \mathrm{C}-\mathrm{NMR}\left(50 \mathrm{MHz}, \mathrm{CDCl}_{3}\right): \delta$ (ppm) 108.5, 110.0, 116.3, 116.8, 121.4, 121.7, 122.3, 128.0, 128.2, 130.4, 135.1, 155.1, 159.3, 164.2, MS: $m / z(\%) 228\left(\mathrm{M}^{+}, 100\right), 199$ (31), 172 (8), 114 (9), 95 (10), 75 (17), 51 (10), HRMS: $m / z$ calculated for $\mathrm{C}_{13} \mathrm{H}_{10} \mathrm{FN}_{2} \mathrm{O}[\mathrm{M}+\mathrm{H}]^{+}: 229.0772$. Found: 229.0769.

1-(2-Fluorophenyl)-1,3-dihydro-2H-benzimidazol-2-one (18). Yield: 69\%, brown resin, THF: $20 \mathrm{~mL}$, purification: silica gel 60, petroleum ether/ethyl acetate 9:1, ${ }^{1} \mathrm{H}-\mathrm{NMR}\left(200 \mathrm{MHz}, \mathrm{CDCl}_{3}\right): \delta(\mathrm{ppm})$ 6.82-6.85 (m, 1H), 7.00-7.19 (m, 3H), 7.26-7.88 (m, 2H), 7.43-7.60 (m, 2H), 10.54 (br s, 1H), ${ }^{13} \mathrm{C}-\mathrm{NMR}\left(50 \mathrm{MHz}, \mathrm{CDCl}_{3}\right): \delta$ (ppm) 108.9, 110.1, 117.0, 117.4, 121.5, 121.9, 122.4, 124.9, 125.0, 128.2, 129.6, 130.4, 154.8, 155.4, 160.5, MS: m/z (\%) $228\left(\mathrm{M}^{+}, 33\right), 199$ (9), 181 (15), 149 (17), 111 (22), 97 (20), 71 (41), 69 (100), 55 (53), 43 (56), HRMS: $m / z$ calculated for $\mathrm{C}_{13} \mathrm{H}_{9} \mathrm{FN}_{2} \mathrm{NaO}[\mathrm{M}+\mathrm{Na}]^{+}$: 251.0597. Found: 251.0592.

3.2.7. Alternative Procedure for the Synthesis of 17 and 18

A solution of $1,1^{\prime}$-carbonyldiimidazole $(1.4 \mathrm{mmol})$ in DMF $(4 \mathrm{~mL})$ was slowly added to a mixture of 14 or $15(1 \mathrm{mmol})$ in DMF (4 mL) under argon atmosphere. The resulting solution was stirred at $90{ }^{\circ} \mathrm{C}$ for $2 \mathrm{~h}$. After completion of the reaction, the solvent was evaporated in vacuo, the slurry was taken up in water, filtered and dried.

1-(4-Fluorophenyl)-1,3-dihydro-2H-benzimidazol-2-one (17). Yield: 80\%, brown resin.

1-(2-Fluorophenyl)-1,3-dihydro-2H-benzimidazol-2-one (18). Yield: 80\%, brown resin.

\subsubsection{General Procedure for the Synthesis of 19-21}

Starting materials 16-18 $(1 \mathrm{mmol})$ and $\mathrm{K}_{2} \mathrm{CO}_{3}(2 \mathrm{mmol})$ were suspended in DMF $(1.8 \mathrm{~mL})$ and stirred at $25{ }^{\circ} \mathrm{C}$ for $30 \mathrm{~min} .11$ and $\mathbf{1 2}$, respectively $(1.5 \mathrm{mmol})$ were added after $30 \mathrm{~min}$ and the solution was stirred at room temperature overnight. To the mixture was added ethyl acetate $(5 \mathrm{~mL})$ and water $(5 \mathrm{~mL})$. The aqueous layer was extracted several times with ethyl acetate $(10 \mathrm{~mL})$ and the combined organic layers were washed with brine, dried over $\mathrm{MgSO}_{4}$ and evaporated to dryness. 
1-(3-Chloro-1-(4-fluorophenyl)propyl)-3-phenyl-1,3-dihydro-2H-benzimidazol-2-one (19). Yield: 32\%, white oil, purification: silica gel 60, petroleum ether/ethyl acetate 8:2, ${ }^{1} \mathrm{H}-\mathrm{NMR}\left(200 \mathrm{MHz}, \mathrm{CDCl}_{3}\right): \delta$ (ppm) 2.70-2.87 (m, 1H), 3.12-3.30 (m, 1H), 3.60-3.66 (m, 2H), $5.73(\mathrm{~m}, 1 \mathrm{H}), 7.00-7.11(\mathrm{~m}, 6 \mathrm{H})$, 7.38-7.57 (m, 7H), ${ }^{13} \mathrm{C}-\mathrm{NMR}\left(50 \mathrm{MHz}, \mathrm{CDCl}_{3}\right): \delta(\mathrm{ppm}) 34.3,42.0,53.8,108.7,109.0,115.5,115.9$, 121.7, 122.0, 126.0, 127.8, 129.2, 129.4, 129.5, MS: $m / z(\%) 380\left(\mathrm{M}^{+}, 21\right), 210(100)\left(\mathrm{M}^{+}-\mathrm{C}_{9} \mathrm{H}_{9} \mathrm{ClF}\right)$, 181 (8), 167 (12), 135 (9), 115 (5), 109 (58), 77 (12), HRMS: $m / z$ calculated for $\mathrm{C}_{22} \mathrm{H}_{18} \mathrm{ClFN}_{2} \mathrm{ONa}$ $[\mathrm{M}+\mathrm{Na}]^{+}:$403.0989. Found: 403.0989 .

1-(3-Chloro-1-phenylpropyl)-3-(4-fluorophenyl)-1,3-dihydro-2H-benzimidazol-2-one (20). Yield: 63\%, dark orange resin, purification: silica gel 60, petroleum ether/ethyl acetate 9:1 and RP-18 silica gel,

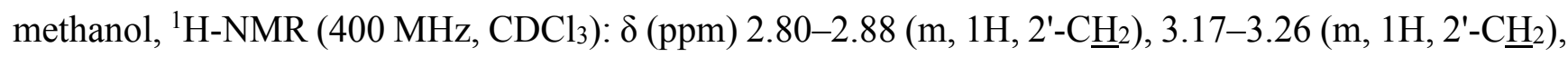
3.62-3.70 (m, 2H, 3'- $\left.\underline{\mathrm{H}}_{2}\right), 5.79\left(\mathrm{dd}, J=10.0 \mathrm{~Hz}\right.$ and $\left.5.6 \mathrm{~Hz}, 1 \mathrm{H}, 1^{\prime}-\mathrm{C} \underline{\mathrm{H}}\right), 7.04-7.09$ (m, 4H, benzim 4-C브,

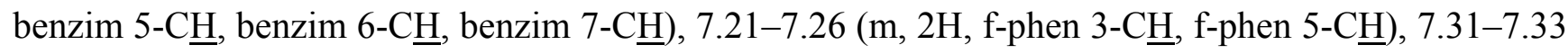

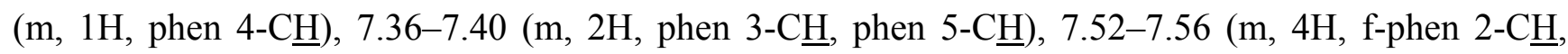

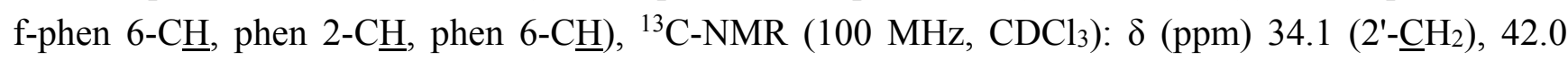

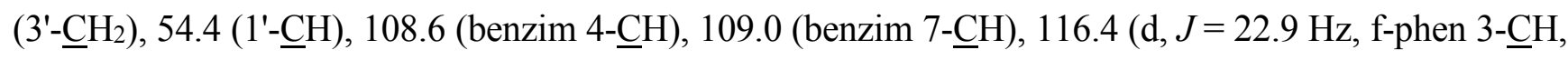

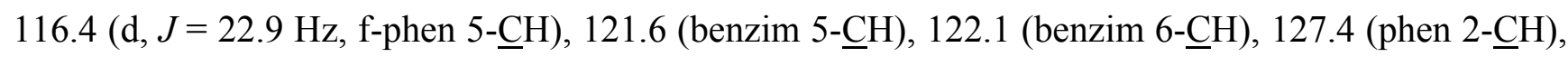

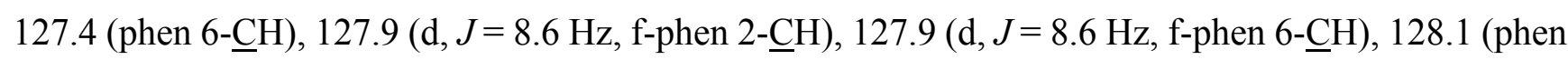

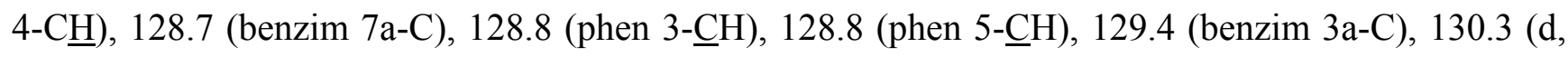
$J=3.1 \mathrm{~Hz}$, f-phen 1-C), 138.4 (phen 1-C), 153.2 (benzim 2-ㅁ), 161.6 (d, $J=247.7 \mathrm{~Hz}$, f-phen 4-타), ${ }^{19} \mathrm{~F}-\mathrm{NMR}\left(471 \mathrm{MHz}, \mathrm{CDCl}_{3}\right): \delta$ (ppm) -113.31 (m, 5-CF), MS: $m / z$ (\%) $380\left(\mathrm{M}^{+}, 2\right), 228(100)$ $\left(\mathrm{M}^{+}-\mathrm{C}_{9} \mathrm{H}_{10} \mathrm{Cl}\right), 199$ (11), 185 (16), 153 (6), 117 (14), 91 (73), 75 (8), HRMS: $m / z$ calculated for $\mathrm{C}_{22} \mathrm{H}_{19} \mathrm{ClFN}_{2} \mathrm{O}[\mathrm{M}+\mathrm{H}]^{+}: 381.1170$. Found: 381.1176 .

1-(3-Chloro-1-phenylpropyl)-3-(2-fluorophenyl-1,3-dihydro-2H-benzimidazol-2-one (21). Yield: 55\%, orange resin, purification: silica gel 60, petroleum ether/ethyl acetate 9:1, ${ }^{1} \mathrm{H}-\mathrm{NMR}\left(400 \mathrm{MHz}, \mathrm{CDCl}_{3}\right)$ : $\delta(\mathrm{ppm}) 2.78-2.86\left(\mathrm{~m}, 1 \mathrm{H}, 2^{\prime}-\mathrm{C}_{2}\right)$ ), 3.23 (br s, 1H, 2'- $\left.\underline{\mathrm{C}}_{2}\right), 3.64-3.68$ (m, 2H, 3'- $\left.\underline{\mathrm{H}}_{2}\right), 5.79$ (br s, 1H,

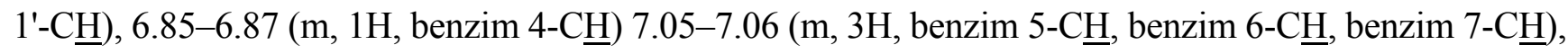

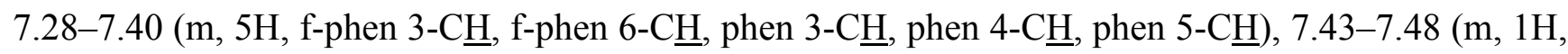
f-phen 4-Cㅂ) $), 7.52-7.56$ (m, 3H, f-phen 5- $\underline{\mathrm{H}}$, phen 2-C $\underline{\mathrm{H}}$, phen $6-\mathrm{CH}),{ }^{13} \mathrm{C}-\mathrm{NMR}\left(100 \mathrm{MHz}, \mathrm{CDCl}_{3}\right)$ :

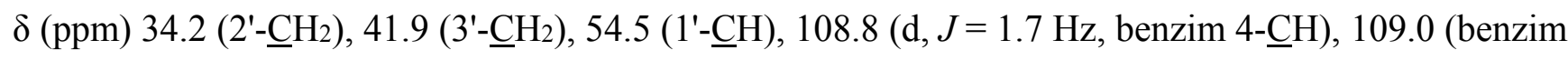

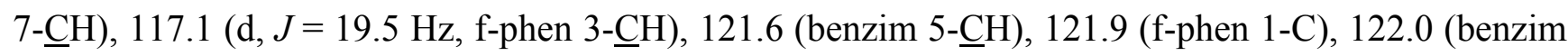

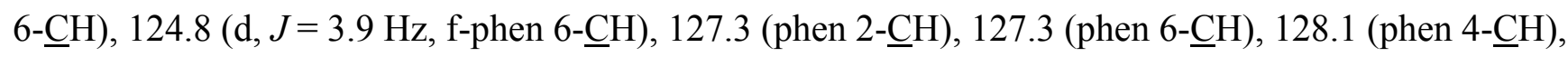

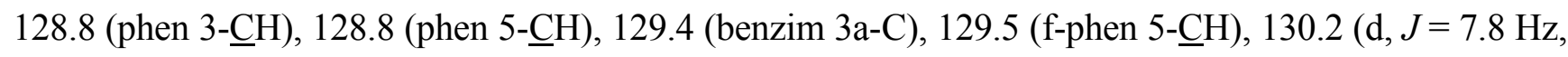
f-phen 4-ㅌH), 138.4 (phen 1-C), 153.0 (benzim 2-ㅡㅇ), 157.9 (d, J=253.2 Hz, f-phen 2-다), due to limited resolution of the measuring apparatus, quaternary carbon benzim $7 \mathrm{a}-\mathrm{C}$ could not be detected, ${ }^{19} \mathrm{~F}-\mathrm{NMR}\left(471 \mathrm{MHz}, \mathrm{CDCl}_{3}\right.$ ): $\delta$ (ppm) -118.39 (m, f-phen 2-CF), MS: $m / z(\%) 380\left(\mathrm{M}^{+}, 12\right), 228(100)$ $\left(\mathrm{M}^{+}-\mathrm{C}_{9} \mathrm{H}_{10} \mathrm{Cl}\right), 199$ (5), 153 (3), 117 (7), 91 (49), 75 (5), HRMS: $m / z$ calculated for $\mathrm{C}_{22} \mathrm{H}_{19} \mathrm{ClFN}_{2} \mathrm{O}$ $[\mathrm{M}+\mathrm{H}]^{+}:$381.1170. Found: 381.1164 . 


\subsubsection{General Procedure for the Synthesis of $\mathbf{2 2 - 2 4}$}

A solution of starting materials 19, 20, or $21(1 \mathrm{mmol})$ and $\mathrm{NaI}(1.03 \mathrm{~g}, 6.89 \mathrm{mmol})$ in acetone $(7 \mathrm{~mL})$ was refluxed for $24 \mathrm{~h}$. The precipitate formed was filtered and the solvent was removed in vacuo.

1-(1-(4-Fluorophenyl)-3-iodopropyl)-3-phenyl-1,3-dihydro-2H-benzimidazol-2-one (22). Yield: 82\%, yellow resin, ${ }^{1} \mathrm{H}-\mathrm{NMR}\left(200 \mathrm{MHz}, \mathrm{CDCl}_{3}\right): \delta(\mathrm{ppm}) 2.77-2.92(\mathrm{~m}, 1 \mathrm{H}), 3.14-3.31(\mathrm{~m}, 3 \mathrm{H}), 5.63-5.70$ (m, 1H), 7.01-7.10 (m, 6H), 7.36-7.56 (m, 7H), ${ }^{13} \mathrm{C}-\mathrm{NMR}\left(50 \mathrm{MHz}, \mathrm{CDCl}_{3}\right): \delta$ (ppm) 2.3, 35.3, 57.0, 108.8, 108.9, 115.5, 115.9, 121.6, 122.0, 126.0, 127.7, 128.5, 129.1, 129.3, 129.4, 134.0, 134.1, 134.3, 153.0, 159.9, 164.8, MS: m/z (\%) $472\left(\mathrm{M}^{+}, 32\right), 317$ (8), $210(100)\left(\mathrm{M}^{+}-\mathrm{C}_{9} \mathrm{H}_{9} \mathrm{~F}\right), 181$ (11), 167 (23), 140 (3), 135 (43), 115 (8), 109 (34), 77 (15), 51 (7), HRMS: $m / z$ calculated for $\mathrm{C}_{22} \mathrm{H}_{18} \mathrm{FIN}_{2} \mathrm{ONa}[\mathrm{M}+\mathrm{Na}]^{+}$: 495.0346. Found: 495.0353.

1-(4-Fluorophenyl)-3-(3-iodo-1-phenylpropyl)-1,3-dihydro-2H-benzimidazol-2-one (23). Yield: 76\%, yellow crystals, mp. $39{ }^{\circ} \mathrm{C}-41{ }^{\circ} \mathrm{C}$, purification: silica gel 60, petrol ether/ethyl acetate 9:1, ${ }^{1} \mathrm{H}-\mathrm{NMR}$

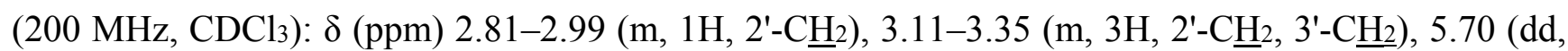

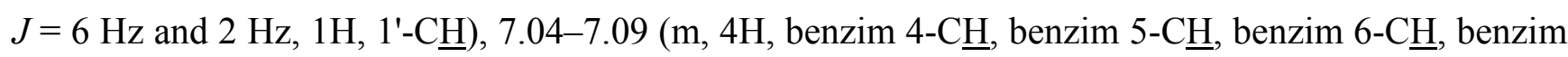

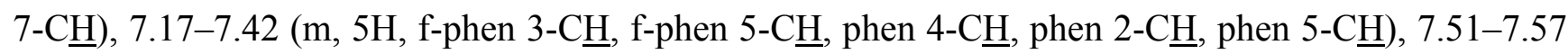

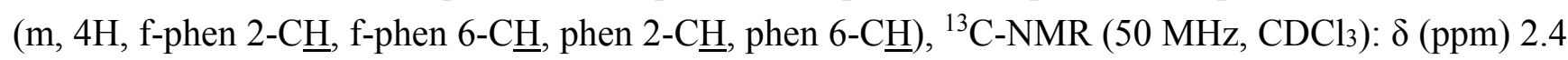

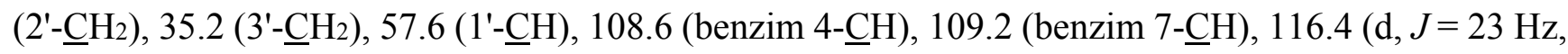

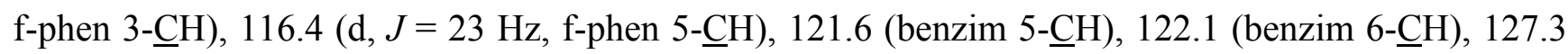

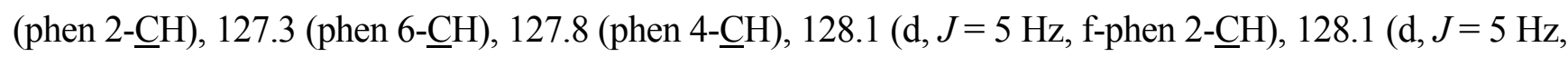

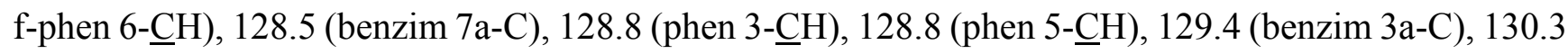
(d, $J=3 \mathrm{~Hz}$, f-phen 1-C), 138.1 (phen 1-C), 153.2 (benzim 2-COO), 161.6 (d, $J=247 \mathrm{~Hz}, \mathrm{f}-$ phen 4-다),

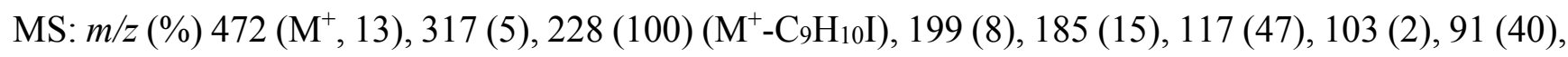
75 (8), 55 (5), HRMS: $m / z$ calculated for $\mathrm{C}_{22} \mathrm{H}_{19} \mathrm{FIN}{ }_{2} \mathrm{O}[\mathrm{M}+\mathrm{H}]^{+}: 473.0526$. Found: 473.0506.

1-(2-Fluorophenyl)-3-(3-iodo-1-phenylpropyl)-1,3-dihydro-2H-benzimidazol-2-one (24). Yield: 53\%, yellow crystals, mp. $38{ }^{\circ} \mathrm{C}-39{ }^{\circ} \mathrm{C}$, purification: silica gel 60, petrol ether/ethyl acetate 9:1, ${ }^{1} \mathrm{H}-\mathrm{NMR}$

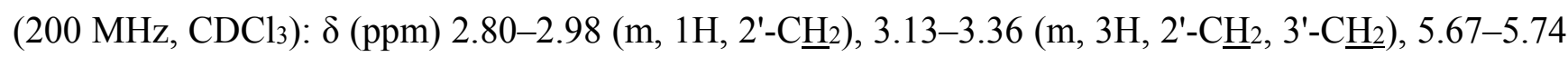

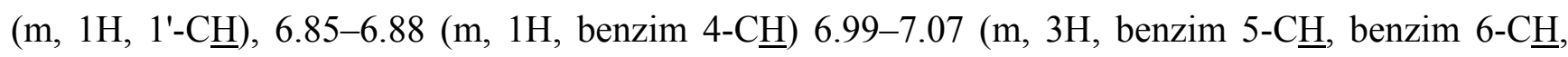

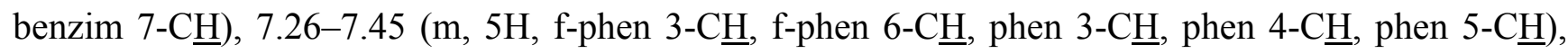

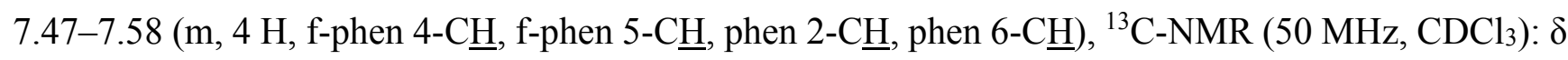
(ppm) $2.3\left(2^{\prime}-\underline{\mathrm{CH}}_{2}\right), 35.4\left(3^{\prime}-\underline{\mathrm{CH}}_{2}\right), 57.6\left(1^{\prime}-\underline{\mathrm{CH}}\right), 108.9$ (d, $J=1.5 \mathrm{~Hz}$, benzim 4-ㅌH), 109.1 (benzim

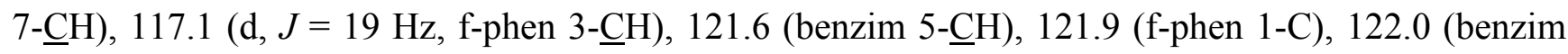
6-타), 124.8 (d, J=3.5 Hz, f-phen 6- $\underline{\mathrm{CH}}$ ), 127.3 (phen 2- $\underline{\mathrm{CH}}$ ), 127.3 (phen 6-ㄷH), 128.1 (phen 4- $\underline{\mathrm{CH}}$ ),

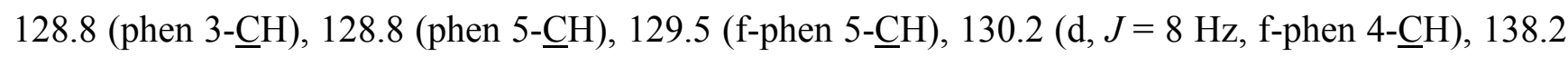
(phen 1-C), 153.0 (benzim 2-ㅁ), 157.8 (d, $J=251.5 \mathrm{~Hz}$, f-phen 2-다), MS: $m / z$ (\%) $472\left(\mathrm{M}^{+}, 9\right), 317$ (5), 241 (4), 228 (100) ( $\left.\mathrm{M}^{+}-\mathrm{C}_{9} \mathrm{H}_{10} \mathrm{I}\right), 199$ (5), 185 (10), 117 (37), 91 (29), 75 (7), HRMS: $m / z$ calculated for $\mathrm{C}_{22} \mathrm{H}_{19} \mathrm{FIN}_{2} \mathrm{O}[\mathrm{M}+\mathrm{H}]^{+}:$473.0526. Found: 473.0532 . 
3.2.10. General procedure for the synthesis of 1-(3-amino-1-(4-fluorophenyl)propyl)-3-phenyl-1,3dihydro-2H-benzimidazol-2-one (25)

1-(1-(4-fluorophenyl)-3-iodopropyl)-3-phenyl-1,3-dihydro-2 $H$-benzimidazol-2-one (0.26 g, $0.55 \mathrm{mmol})$ and a solution of $\mathrm{NH}_{3}$ in isopropanol $(2 \mathrm{M}, 22 \mathrm{~mL})$ were heated in a sealed tube for $3 \mathrm{~h}$ at $80{ }^{\circ} \mathrm{C}$. After evaporation of the solvent, the crude product was purified by column chromatography (silica gel 60 , $\left.\mathrm{CH}_{2} \mathrm{Cl}_{2} / \mathrm{MeOH} 9: 1\right)$. Yield: $0.10 \mathrm{~g}$ (50\%), light brown crystals, mp. 87-88 ${ }^{\circ} \mathrm{C}$. ${ }^{1} \mathrm{H}-\mathrm{NMR}(400 \mathrm{MHz}$, $\left.\mathrm{CDCl}_{3}\right): \delta(\mathrm{ppm})$ 2.74-2.84 (m, 3H, 2'- $\left.\underline{\mathrm{H}}_{2}, 3^{\prime}-\mathrm{C}_{2}\right), 2.98-3.04\left(\mathrm{~m}, 1 \mathrm{H}, 3{ }^{\prime}-\underline{\mathrm{H}}_{2}\right), 5.74-5.78(\mathrm{~m}, 1 \mathrm{H}$,

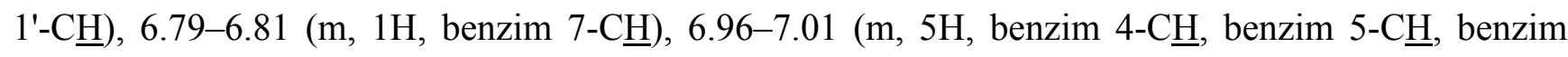

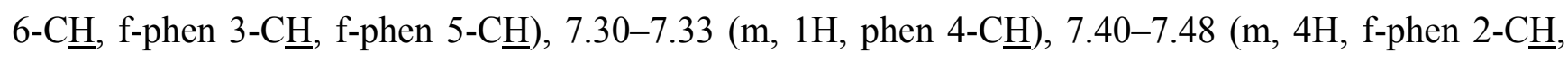

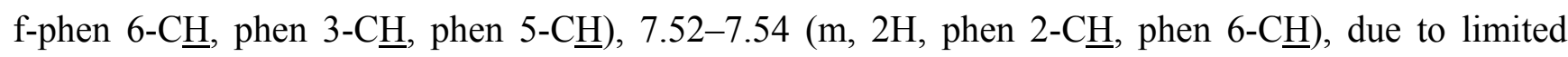
resolution of the instrumentation, the $\mathrm{NH}_{2}$ protons could not be detected, ${ }^{13} \mathrm{C}-\mathrm{NMR}\left(100 \mathrm{MHz}, \mathrm{CDCl}_{3}\right)$ :

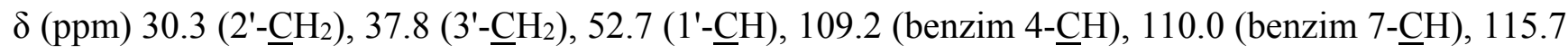
(d, $J=21.5 \mathrm{~Hz}$, f-phen 3-ㅌH ), 115.7 (d, $J=8.2 \mathrm{~Hz}$, f-phen 5-ㅌH), 122.0 (benzim 5-ㅌH), 122.3 (benzim

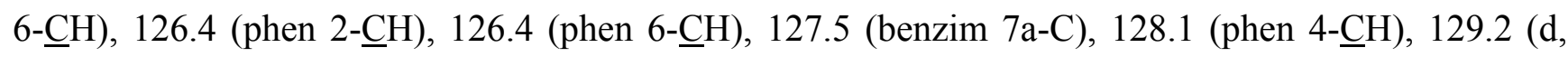

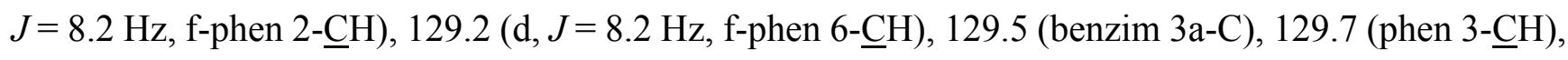

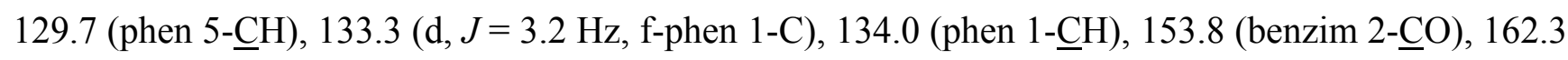
(d, $J=247.4 \mathrm{~Hz}$, f-phen 4-다), ${ }^{19} \mathrm{~F}-\mathrm{NMR}\left(471 \mathrm{MHz}, \mathrm{CDCl}_{3}\right): \delta(\mathrm{ppm})-113.68$ (m, f-phen CEF), MS: $m / z$ (\%) 361 ( $\left.\mathrm{M}^{+}, 17\right), 331$ (10), 210 (100) ( $\left.\mathrm{M}^{+}-\mathrm{C}_{9} \mathrm{H}_{11} \mathrm{FN}\right), 181$ (15), 167 (16), 149 (29), 128 (17), 77 (19), 57 (20), 43 (12), HRMS: $m / z$ calculated for $\mathrm{C}_{22} \mathrm{H}_{21} \mathrm{FN}_{3} \mathrm{O}[\mathrm{M}+\mathrm{H}]^{+}: 362.1669$. Found: 362.1674.

\subsubsection{General Procedure for the Synthesis of 4-6}

Starting materials 18, 19 or $\mathbf{2 0}(1 \mathrm{mmol})$ and a solution of methylamine in EtOH $(12.5 \mathrm{~mL}, 8 \mathrm{M})$ were heated in a sealed tube for $3 \mathrm{~h}$ at $80{ }^{\circ} \mathrm{C}$. After evaporation of the solvent, the crude reaction product was purified by column chromatography.

\section{1-(1-(4-Fluorophenyl)-3-(methylamino)propyl)-3-phenyl-1,3-dihydro-2H-benzimidazol-2-one}

Yield: 48\%, light orange resin, purification: silica gel 60, dichloromethane/methanol 9:1 and dichloromethane/ethyl acetate/methanol 7:2:1, ${ }^{1} \mathrm{H}-\mathrm{NMR}\left(400 \mathrm{MHz}, \mathrm{CDCl}_{3}\right): \delta(\mathrm{ppm}) 2.42(\mathrm{~s}, 3 \mathrm{H}$,

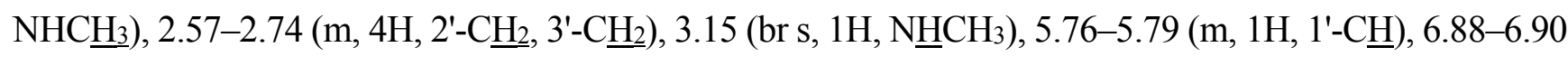

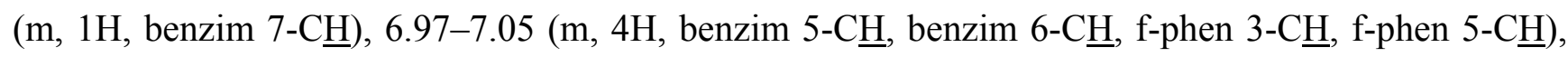

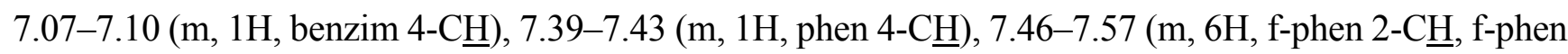

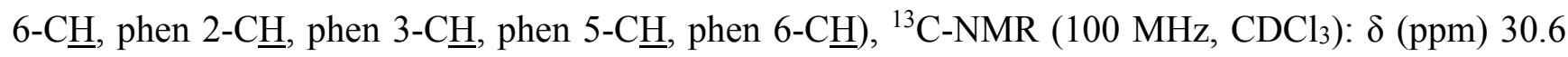

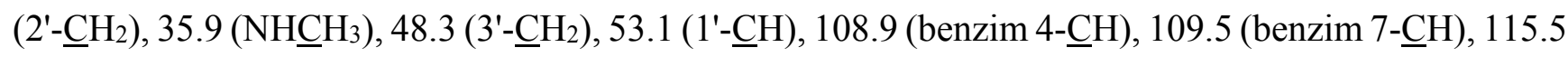

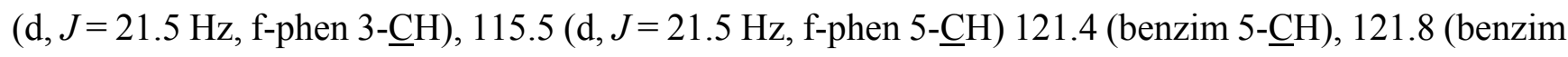

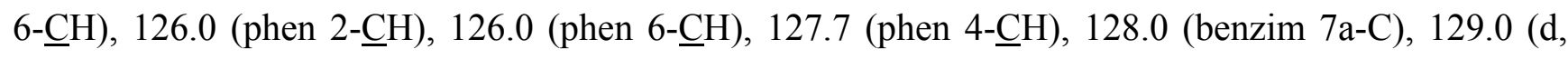

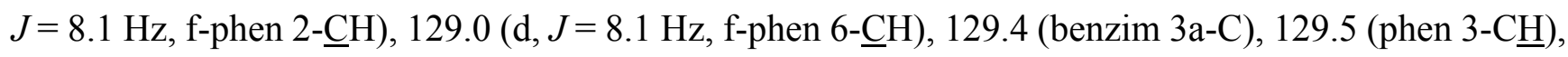

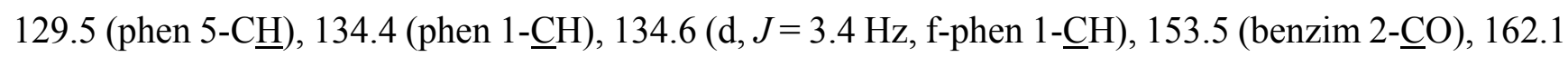
(d, $J=246.7 \mathrm{~Hz}$, f-phen 4-다), ${ }^{19} \mathrm{~F}-\mathrm{NMR}\left(471 \mathrm{MHz}, \mathrm{CDCl}_{3}\right): \delta$ (ppm) -114.36 (m, f-phen 4-CF), MS: $m / z(\%) 375\left(\mathrm{M}^{+}, 16\right), 210(57)\left(\mathrm{M}^{+}-\mathrm{C}_{10} \mathrm{H}_{13} \mathrm{FN}\right), 181$ (10), 167 (12), 150 (10), 109 (22), 97 (16), 71 (27), 57 (78), 44 (100), HRMS: $m / z$ calculated for $\mathrm{C}_{23} \mathrm{H}_{23} \mathrm{FN}_{3} \mathrm{O}[\mathrm{M}+\mathrm{H}]^{+}: 376.1825$. Found: 376.1821 . 
1-(4-Fluorophenyl)-3-(3-(methylamino)-1-phenylpropyl)-1,3-dihydro-2H-benzimidazol-2-one

Yield: 29\%, light yellow crystals, mp. $100{ }^{\circ} \mathrm{C}-102{ }^{\circ} \mathrm{C}$, purification: silica gel 60, dichloromethane/methanol 9:1 and RP-18 silica gel methanol/water 9:1 and 7:3, ${ }^{1} \mathrm{H}-\mathrm{NMR}(200 \mathrm{MHz}$,

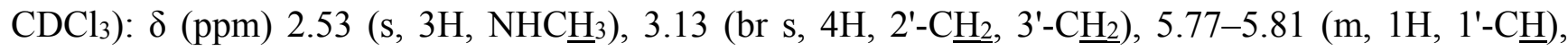

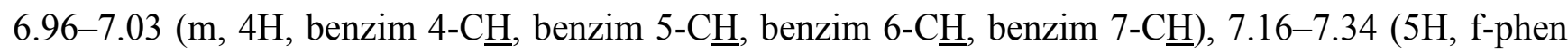

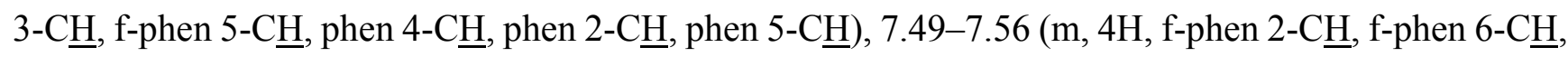
phen $2-\mathrm{C} \underline{H}$, phen $6-\mathrm{CH})$, due to limited resolution of the instrumentation, the $\underline{\mathrm{H}}$ proton could not be detected, ${ }^{13} \mathrm{C}-\mathrm{NMR}\left(50 \mathrm{MHz}, \mathrm{CDCl}_{3}\right): \delta(\mathrm{ppm}) 27.6\left(2^{\prime}-\underline{\mathrm{CH}}_{2}\right), 33.1\left(\mathrm{NHCH}_{3}\right), 47.0\left(3^{\prime}-\underline{\mathrm{CH}}_{2}\right), 54.2$

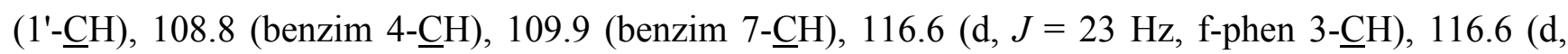

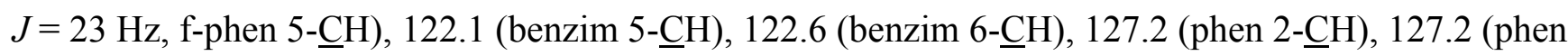

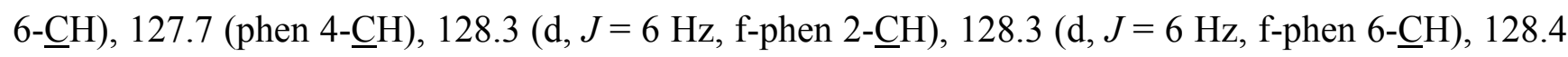
(benzim 7a-C), 128.9 (phen 3-ㅌH), 128.9 (phen 5-ㅌH), 129.2 (benzim 3a-C), 129.7 (d, J=3 Hz, f-phen 1-C), 136.9 (phen 1-C), 153.4 (benzim 2-ㅁ), 161.7 (d, $J=248 \mathrm{~Hz}, \mathrm{f}-\mathrm{phen} 4-\underline{\mathrm{C} F}$ ), MS: $m / z$ (\%) 375 $\left(\mathrm{M}^{+}, 11\right), 330$ (7), $228(50)\left(\mathrm{M}^{+}-\mathrm{C}_{10} \mathrm{H}_{14} \mathrm{~N}\right), 199$ (7), 185 (9), 147 (17), 128 (26), 117 (8), 91 (13), 58 (34), 44 (100), HRMS: $m / z$ calculated for $\mathrm{C}_{23} \mathrm{H}_{23} \mathrm{FN}_{3} \mathrm{O}[\mathrm{M}+\mathrm{H}]^{+}:$376.1825. Found: 376.1828.

\section{1-(2-Fluorophenyl)-3-(3-(methylamino)-1-phenylpropyl)-1,3-dihydro-2H-benzimidazol-2-one}

Yield: $30 \%$, yellow crystals, mp. $92{ }^{\circ} \mathrm{C}-93{ }^{\circ} \mathrm{C}$, purification: silica gel 60, dichloromethane/methanol 9:1 and RP-18 silica gel methanol/water 9:1 and 7:3, ${ }^{1} \mathrm{H}-\mathrm{NMR}\left(200 \mathrm{MHz}, \mathrm{CDCl}_{3}\right): \delta(\mathrm{ppm}) 2.57(\mathrm{~s}, 3 \mathrm{H}$, $\left.\mathrm{NHC}_{\underline{H}}\right), 3.01-3.15\left(\mathrm{~m}, 4 \mathrm{H}, 2^{\prime}-\underline{\mathrm{C}}_{2}, 3^{\prime}-\underline{\mathrm{C}}_{2}\right), 5.75-5.86\left(\mathrm{~m}, 1 \mathrm{H}, 1^{\prime}-\mathrm{C} \underline{\mathrm{H}}\right), 6.83-6.87$ (m, 1H, benzim 4-C $\left.\underline{\mathrm{H}}\right)$

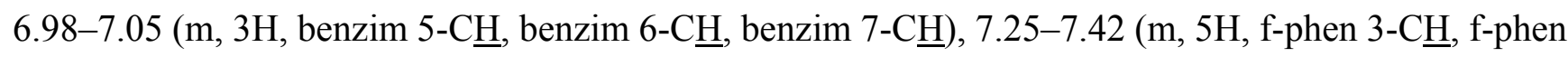

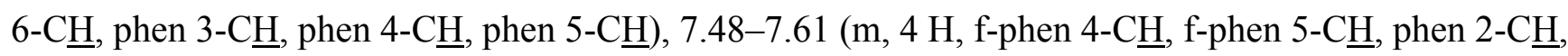
phen 6-C프), due to limited resolution of the instrumentation, the $\mathrm{NHCH}_{3}$ proton could not be detected,

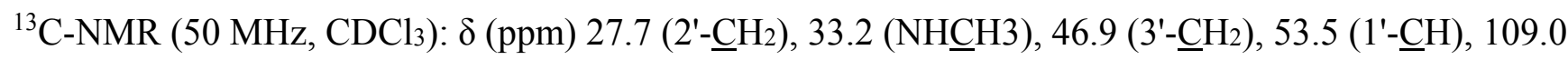

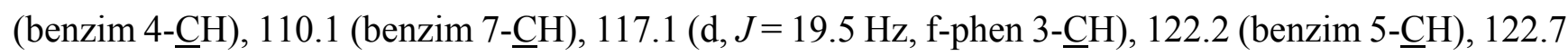
(benzim 6-ㅌH), 125.1 (d, J=3.0 Hz, f-phen 6- $\underline{\mathrm{CH}}$ ), 127.3 (phen 2- $\underline{\mathrm{CH}}$ ), 127.1 (phen 6-ㅡH), 128.3 (phen

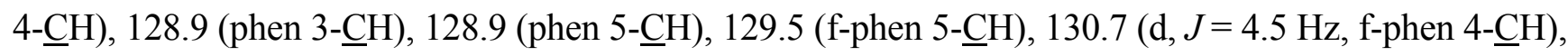
136.5 (phen 1-C), 153.6 (benzim 2-ㅡㅇ), 157.6 (d, $J=250.5 \mathrm{~Hz}$, f-phen 2-다), due to limited resolution of the measuring apparatus, quaternary carbon f-phen 1-C could not be detected, MS: $m / z(\%) 375\left(\mathrm{M}^{+}\right.$, 17), 318 (10), 228 (82) ( $\left.\mathrm{M}^{+}-\mathrm{C}_{10} \mathrm{H}_{14} \mathrm{~N}\right), 199$ (9), 185 (9), 147 (16), 128 (35), 117 (9), 91 (20), 58 (43), 44 (100), HRMS: $m / z$ calculated for $\mathrm{C}_{23} \mathrm{H}_{23} \mathrm{FN}_{3} \mathrm{O}[\mathrm{M}+\mathrm{H}]^{+}: 376.1825$. Found: 376.1822.

\subsection{Computational Methods}

The ligand structures were built in the protonated form using Molecular Operating Environment (MOE) 2013 [42]. Homology models of human NET, SERT and DAT were obtained from the

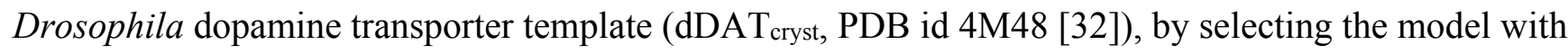
the most favorable Discrete Optimized Protein Energy (DOPE) of 250 generated by Modeller 9.11 [43]. The co-crystallized inhibitor nortriptyline was retained during model generation and the compounds were docked in the same site using Genetic Optimization for Ligand Docking (GOLD) 5.2 [44]. One hundred poses per ligand (i.e., five hundred poses per protein target) were generated based on the GoldScore scoring function, while keeping the ligand flexible and the protein rigid. 
The common chemical scaffold, i.e., the reference compound, was extracted from the resulting poses, analogous to the methods of our previous study [35]. Cluster analysis was performed based on Euclidian distance and complete linkage of the root-mean square deviation of the ligand's heavy atoms matrix using XLStat [45]. The dendrogram was cut at eight clusters and the ones containing all five ligands were selected (Figure 5).

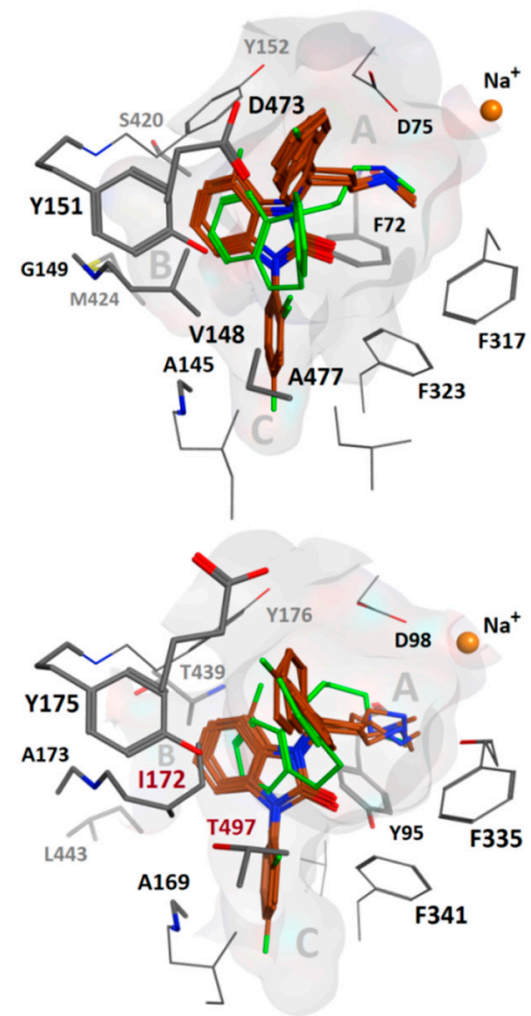

NET
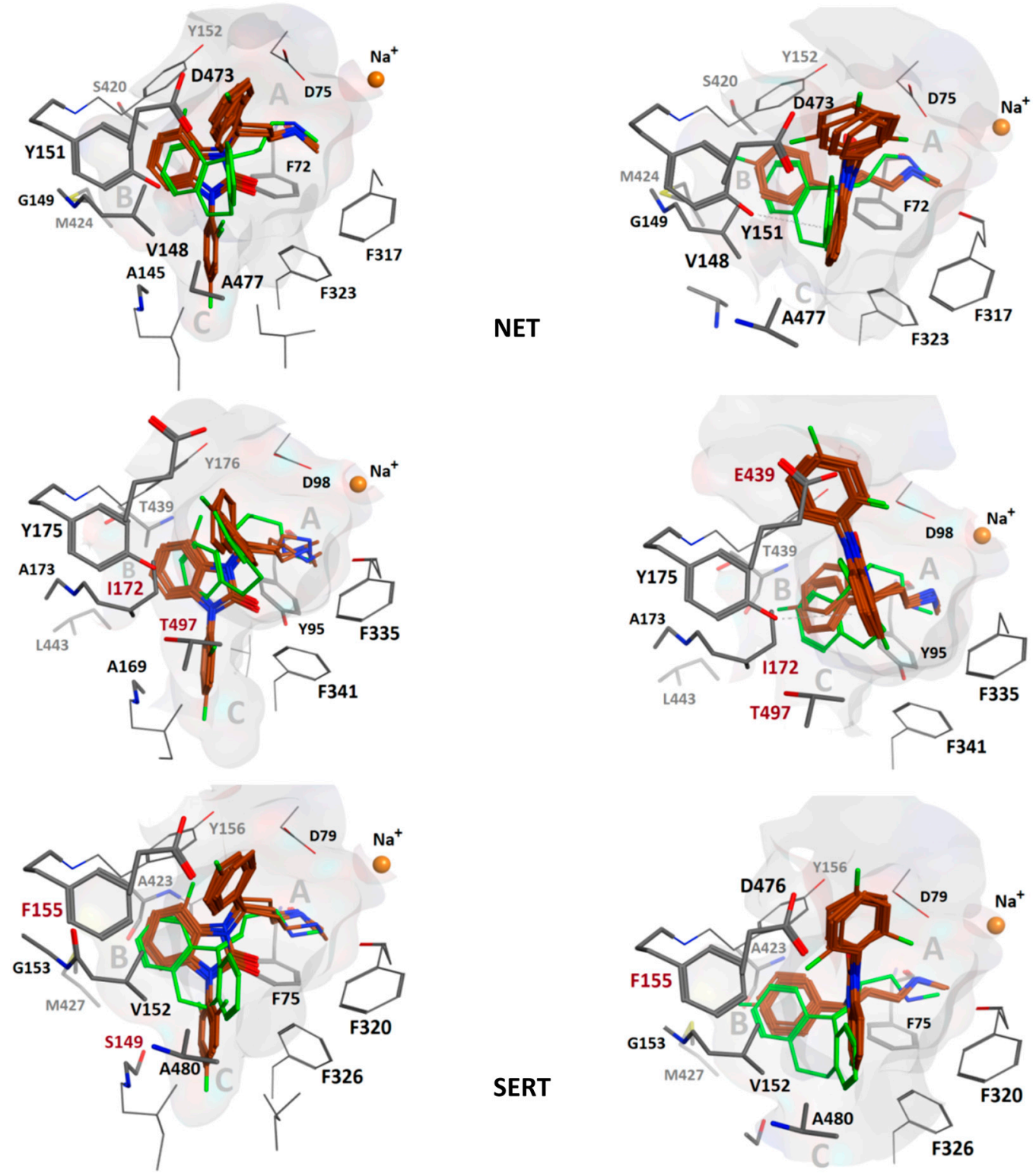

Figure 5. Left column: Overlay of compounds 1, 2, and 4-6 (maroon) in binding hypothesis 1 and comparison with the co-crystal pose of nortriptyline (31) (green). In NET, V148 allows more space than I172 in SERT. The angle between ligand ring 2 and 3 is $c a .60^{\circ}$ in all poses. Right column: Overlay of compounds 1, 2, and 4-6 (maroon) in binding hypothesis 2 . In NET, V148 still allows more space than in hSERT, whereas E439 might disrupt ligand ring 3. DAT lacks a more potent stacking interaction due to F155 as compared to NET[Y151] and SERT[Y175]. Binding mode 2 poses are more in agreement with the co-crystal pose. The angle between ligand ring 2 and 3 is almost $90^{\circ}$ in all poses. The extracellular space is located above in all figures. 


\section{Conclusions}

In conclusion, ten new compounds have been synthesized within the scope of this work, which aimed at the development of new, selective, high affinity references for the imaging of the NET system via PET. Four of these new compounds (4-6 and 25) will be employed in future studies. Whilst methylamines 4-6 (FAPPI:1-3) represent reference compounds for their later prepared radioactive analogs, additionally prepared free amine 25 (APPI:1) will serve as precursor for radiolabeling. Since docking studies indicate that fluorinated methyl amines 4-6 (FAPPI:1-3) bind in an analogous way to the NET as reference compound 1, these compounds 4-6 are promising candidates for biological evaluation.

\section{Acknowledgments}

AS, AJ, and GFE acknowledge financial support provided by the Austrian Science Fund, grants AW/0123221 and F3502. This article was supported by the Open Access Publishing Fund of the University of Vienna.

\section{Author Contributions}

Catharina Neudorfer: Responsible for the performance of the syntheses and writing; Amir Seddik: Structure activity relationships calculations; Karem Shanab: Contributions to syntheses and experimental procedures; Andreas Jurik: Structure activity relationships calculations; Christina Rami-Mark: Participated in design and performance of the experiments; Wolfgang Holzer: Performance of the NMR analyses; Gerhard Ecker: Conceived and supervised the SAR experiments; Markus Mitterhauser: Designed parts of the research and proofread the manuscript; Wolfgang Wadsak: Designed parts of the research and proofread the manuscript; Helmut Spreitzer: Conceived and supervised the syntheses.

\section{Conflicts of Interest}

The authors declare no conflict of interest.

\section{References}

1. Sung, U.; Apparsundram, S.; Galli, A.; Kahlig, K.M.; Savchenko, V.; Schroeter, S.; Quick, M.W.; Blakely, R.D. A regulated interaction of syntaxin 1A with the antidepressant-sensitive norepinephrine transporter establishes catecholamine clearance capacity. J. Neurosci. 2003, 23, 1697-1709.

2. Kim, C.H.; Hahn, M.K.; Joung, Y.; Anderson, S.L.; Steele, A.H.; Mazei-Robinson, M.S.; Gizer, I.; Teicher, M.H.; Cohen, B.M.; Robertson, D.; et al. A polymorphism in the norepinephrine transporter gene alters promoter activity and is associated with attention-deficit hyperactivity disorder. Proc. Natl. Acad. Sci. USA 2006, 103, 19164-19169.

3. Hahn, M.K.; Robertson, D.; Blakely, R.D. A mutation in the human norepinephrine transporter gene (SLC6A2) associated with orthostatic intolerance disrupts surface expression of mutant and wild-type transporters. J. Neurosci. 2003, 23, 4470-4478. 
4. Mirbolooki, M.R.; Upadhyay, S.K.; Constantinescu, C.C.; Pan, M.L.; Mukherjee, J. Adrenergic pathway activation enhances brown adipose tissue metabolism: A $\left[{ }^{18} \mathrm{~F}\right] \mathrm{FDG}$ PET/CT study in mice. Nucl. Med. Biol. 2014, 41, 10-16.

5. Lin, S.L.; Fan, X.; Yeckel, C.W.; Weinzimmer, D.; Mulnix, T.; Gallezot, J.D.; Carson, R.E.; Sherwin, R.S.; Ding, Y.S. Ex vivo and in vivo Evaluation of the Norepinephrine Transporter Ligand $\left[{ }^{11} \mathrm{C}\right] \mathrm{MRB}$ for Brown Adipose Tissue Imaging. Nucl. Med. Biol. 2012, 39, 1081-1086.

6. Stöber, G.; Nöthen, M.M.; Pörzgen, P.; Brüss, M.; Bönisch, H.; Knapp, M.; Beckmann, H.; Propping, P. Systematic search for variation in the human norepinephrine transporter gene: Identification of five naturally occurring missense mutations and study of association with major psychiatric disorders. Am. J. Med. Genet. (Neuropsychiatr. Genet.) 1996, 67, 523-532.

7. Young, J.B.; Landsberg, L. Catecholamines and the adrenal medulla. In Williams Textbook of Endocrinology, 9th ed.; Wilson, J.D., Foster, D.W., Eds.; W.B. Saunders Co.: Philadelphia, PA, USA, 1998; p. 680.

8. Tellioglu, T.; Robertson, D. Genetic or acquired deficits in the norepinephrine transporter: Current understanding of clinical implications. Exp. Rev. Mol. Med. 2001, 1-10.

9. Blakely, R.D.; Bauman, A.L. Biogenic amine transporters: regulation in flux. Curr. Opin. Neurobiol. 2000, 10, 328-336.

10. Zhu, M.Y; Shamburger, S.; Li, J.; Ordway, G.A. Regulation of the Human Norepinephrine Transporter by Cocaine and Amphetamine. J. Pharmacol. Exp. Ther. 2000, 295, 951-959.

11. Moron, J.A.; Brockington, A.; Wise, R.A.; Rocha, B.A.; Hope, B.T. Dopamine Uptake through the Norepinephrine Transporter in Brain Regions with Low Levels of the Dopamine Transporter: Evidence from Knock-Out Mouse Lines. J. Neurosci. 2002, 22, 386-395.

12. Schroeter, S.; Apparsundaram, S.; Wiley, R.G.; Miner, L.H.; Sesack, S.R.; Blakely, R.D. Immunolocalization of the cocaine- and antidepressant-sensitive 1-norepinephrine transporter. J. Comp. Neurol. 2000, 420, 211-232.

13. Torres, G.E.; Gainetdinov, R.R.; Caron, M.G. Plasma membrane monoamine transporters: Structure, regulation and function. Nat. Rev. Neurosci. 2003, 4, 13-25.

14. Ordway, G.A.; Stockmeier, C.A.; Cason, G.W.; Klimek, V. Pharmacology and Distribution of Norepinephrine Transporters in the Human Locus Coeruleus and Raphe Nuclei. J. Neurosci. 1997, 17, 1710-1719.

15. Smith, H.R.; Beveridge, T.J. R.; Porrino, L.J. Distribution of norepinephrine transporters in the non-human primate brain. Neuroscience 2006, 138, 703-714.

16. Zhou, J. Norepinephrine transporter inhibitors and their therapeutic potential. Drugs Future 2004, $29,1235-1244$.

17. Curatolo, P.; D’Agati, E.; Moavero, R. The neurobiological basis of ADHD. Ital. J. Pediatr. 2010, 36,79 .

18. Mash, D.C.; Ouyang, Q.; Qin, Y.; Pablo, J. Norepinephrine transporter immunoblotting and radioligand binding in cocaine abusers. Neurosci. Methods 2005, 143, 79-85.

19. Barr, C.L.; Kroft, J.; Feng, Y.; Wigg, K.; Roberts, W.; Malone, M.; Ickowicz, A.; Schachar, R.; Tannock, R.; Kennedy, J.L. The Norepinephrine Transporter Gene and Attention-Deficit Hyperactivity Disorder. Am. J. Med. Genet. (Neuropsychiatr. Genet.) 2002, 114, 255-229. 
20. Klimek, V.; Stockmeier, C.; Overholser, J.; Meltzer, H.Y.; Kalka, S.; Dilley, G.; Ordway, G.A. Reduced Levels of Norepinephrine Transporters in the Locus Coeruleus in Major Depression. J. Neurosci. 1997, 17, 8451-8458.

21. Nedergaard, J.; Cannon, B. The changed metabolic world with human brown adipose tissue: Therapeutic visions. Cell Metab. 2010, 11, 268-272.

22. Gulyas, B.; Brockschnieder, D.; Nag, S.; Pavlova, E.; Kasa, P.; Beliczai, Z.; Legradi, A.; Gulya, K.; Thiele, A.; Dyrks, T.; et al. The norepinephrine transporter radioligand [18F]FD2MeNER shows significant decreases in NET density in the locus coeruleus and the thalamus in Alzheimer's disease: A post-mortem autoradiographic study in human brains. Neurochem. Int. 2010, 56, 789-798.

23. Wilson, A.A.; Johnson, D.P.; Mozley, D.; Hussey, D.; Ginovart, N.; Nobrega, J.; Garcia, A.; Meyer, J.; Houle, S. Synthesis and in vivo evaluation of novel radiotracers for the in vivo imaging of the norepinephrine transporter. Nucl. Med. Biol. 2003, 30, 85-92.

24. Takano, A.; Gulyas, B.; Varrone, A.; Halldin, C. Saturated norepinephrine transporter occupancy by atomoxetine relevant to clinical doses: a rhesus monkey study with (S,S)-[(18)F]FMeNER-D (2). Eur. J. Nucl. Med. Mol. Imaging 2009, 36, 1308-1314.

25. Schou, M.; Zoghbi, S.S.; Shetty, H.U.; Shchukin, E.; Liow, J.S.; Hong, J.; Andrée, B.A.; Gulyás, B.; Farde, L.; Innis, R.B.; et al. Investigation of the metabolites of $\left[{ }^{11} \mathrm{C}\right](\mathrm{S}, \mathrm{S})-\mathrm{MeNER}$ in humans, monkeys and rats. Mol. Imaging Biol. 2009, 11, 23-30.

26. Zhang, P.; Terefenko, E.A.; McComas, C.C.; Mahaney, P.E.; Vu, A.; Trybulski, E.; Koury, E.; Johnston, G.; Bray, J.; Deecher, D. Synthesis and activity of novel 1- or 3-(3-amino-1-phenyl propyl)-1,3-dihydro-2 $H$-benzimidazol-2-ones as selective norepinephrine reuptake inhibitors. Bioorg. Med. Chem. Lett. 2008, 18, 6067-6070.

27. Mark, C.; Bornatowicz, B.; Mitterhauser, M.; Hendl, M.; Nics, L.; Haeusler, D.; Lanzenberger, R.; Berger, M.L.; Spreitzer, H.; Wadsak, W. Development and automation of a novel NET-PET tracer: [C-11]Me@APPI. Nucl. Med.Biol. 2013, 40, 295-303.

28. Varney, M.D.; Romines, W.H.; Boritzki, T.; Margosiak, S.A.; Barlett, C.; Howland, E.J. Synthesis and biological evaluation of -n[4-(2-trans-[([2,6-diamino-4(3H)-oxopyrimidin-5yl]methyl)thio]cyclobutyl)benzoyl] -l-glutamic acid a novel 5-thiapyrimidinone inhibitor of dihydrofolate reductase. J. Heterocycl. Chem. 1995, 32, 1493-1498.

29. Xu, Z.B.; Lu, Y.; Guo, Z.R. An Efficient and Fast Procedure for the Preparation of 2-Nitrophenylamines under Microwave Conditions. Synlett 2003, 4, 564-566.

30. Wang, X.J.; Xi, M.Y.; Fu, J.H.; Zhang, F.R.; Cheng, G.F.; Yin, D.L.; You, Q.D. Synthesis, biological evaluation and SAR studies of benzimidazole derivatives as $\mathrm{H}_{1}$-antihistamine agents. Chin. Chem. Lett. 2012, 23, 707-710.

31. Jona, H.; Shibata, J.; Asai, M.; Goto, Y.; Arai, S.; Nakajima, S.; Okamoto, O.; Kawamoto, H.; Iwasawa, Y. Efficient and practical asymmetric synthesis of 1-tert-butyl 3-methyl (3R,4R)-4-(2-oxo2,3-dihydro-1 $H$-benzimidazol-1-yl)piperidine-1,3-dicarboxylate, a useful intermediate for the synthesis of nociceptin antagonists. Tetrahedron: Asymmetry 2009, 20, 2439-2446.

32. Penmatsa, A.; Wang, K.H.; Gouaux, E. X-ray structure of dopamine transporter elucidates antidepressant mechanism. Nature 2013, 503, 85-90.

33. Wang, H.; Goehring, A.; Wang, K.H.; Penmatsa, A.; Ressler, R.; Gouaux, E. Structural basis for action by diverse antidepressants on biogenic amine transporters. Nature 2013, 503, 141-145. 
34. Tatsumi, M.; Groshan, K.; Blakely, R.D.; Richelson, E. Pharmacological profile of antidepressants and related compounds at human monoamine transporters. Eur. J. Pharmacol. 1997, 340, 249-258.

35. Richter, L.; de Graaf, C.; Sieghart, W.; Varagic, Z.; Morzinger, M.; de Esch, I.J.; Ecker, G.F.; Ernst, M. Diazepam-bound GABAA receptor models identify new benzodiazepine binding-site ligands. Nat. Chem. Biol. 2012, 8, 455-464.

36. Andersen, J.; Olsen, L.; Hansen, K.B.; Taboureau, O.; Jorgensen, F.S.; Jorgensen, A.M.; Bang-Andersen, B.; Egebjerg, J.; Stromgaard, K.; Kristensen, A.S. Mutational Mapping and Modeling of the Binding Site for (S)-Citalopram in the Human Serotonin Transporter. J. Biol. Chem. 2010, 285, 2051-2063.

37. Chelli, R.; Gervasio, F.L.; Procacci, P.; Schettino, V. Stacking and T-shape Competition in Aromatic-Aromatic Amino Acid Interactions. J. Am. Chem. Soc. 2002, 124, 6133-6143.

38. Yu, F.; Zhou, J.N.; Zhang, X.C.; Sui, Y.Z.; Wu, F.F.; Xie, L.J.; Chan, A.S.C.; Wu, J. Copper(II)-Catalyzed Hydrosilylation of Ketones Using Chiral Dipyridylphosphane Ligands: Highly Enantioselective Synthesis of Valuable Alcohols. Chemistry 2011, 17, 14234-14240.

39. La Regina, G.; Diodata D’Auria, F.; Tafi, A.; Piscitelli, F.; Olla, S.; Caporuscio, F.; Nencioni, L.; Cirilli, R.; La Torre, F.; Rodrigues De Melo, N.; et al. 1-[(3-Aryloxy-3-aryl)propyl]-1H-imidazoles, new imidazoles with potent activity against Candida albicans and dermatophytes. Synthesis, structure-activity relationship, and molecular modeling studies. J. Med. Chem. 2008, 51, 3841-3855.

40. Panagopoulos, A.M.; Steinman, D.; Goncharenko, A.; Geary, K.; Schleisman, C.; Spaargaren, E.; Zeller, M.; Becker, D.P. Apparent Alkyl Transfer and Phenazine Formation via an Aryne Intermediate. J. Org. Chem. 2013, 78, 3532-3540.

41. Liu, P.; Wang, Z.; Hu, X. Highly Efficient Synthesis of Ureas and Carbamates from Amides by Iodosylbenzene-Induced Hofmann Rearrangement. Eur. J. Org. Chem. 2012, 10, 1994-2000.

42. Molecular Operating Environment (MOE); Chemical Computing Group Inc.: Montreal, QC, Canada, 2013.

43. Sali, A.; Potterton, L.; Yuan, F.; van Vlijmen, H.; Karplus, M. Evaluation of comparative protein modeling by MODELLER. Proteins 1995, 23, 318-326.

44. Jones, G.; Willett, P.; Glen, R.C.; Leach, A.R.; Taylor, R. Development and validation of a genetic algorithm for flexible docking. J. Mol. Biol. 1997, 267, 727-748.

45. XLStat; Addinsoft Inc.: New York, NY, USA, 2009.

Sample Availability: Samples of the compounds 4-6, 9-25, and 29 and $\mathbf{3 0}$ are available from the authors.

(C) 2015 by the authors; licensee MDPI, Basel, Switzerland. This article is an open access article distributed under the terms and conditions of the Creative Commons Attribution license (http://creativecommons.org/licenses/by/4.0/). 